\title{
Defective $N$-sulfation of heparan sulfate proteoglycans limits PDGF-BB binding and pericyte recruitment in vascular development
}

\author{
Alexandra Abramsson, ${ }^{1,6}$ Sindhulakshmi Kurup, ${ }^{2,6}$ Marta Busse, ${ }^{3}$ Shuhei Yamada, ${ }^{2,7}$ \\ Per Lindblom, ${ }^{3,8}$ Edith Schallmeiner, ${ }^{4}$ Denise Stenzel, ${ }^{3}$ Dominique Sauvaget, ${ }^{3}$ Johan Ledin, ${ }^{2}$ \\ Maria Ringvall, ${ }^{2}$ Ulf Landegren, ${ }^{4}$ Lena Kjellén, ${ }^{2}$ Göran Bondjers, ${ }^{5}$ Jin-ping Li, ${ }^{2}$ Ulf Lindahl, ${ }^{2}$ \\ Dorothe Spillmann, ${ }^{2}$ Christer Betsholtz, ${ }^{1}$ and Holger Gerhardt ${ }^{3,9}$ \\ ${ }^{1}$ Department of Medical Biochemistry and Biophysics, Division of Matrix Biology, Karolinska Institute, SE-171 77 \\ Stockholm, Sweden; ${ }^{2}$ Department of Medical Biochemistry and Microbiology, University of Uppsala, SE-751 23 Uppsala, \\ Sweden; ${ }^{3}$ Vascular Biology Laboratory, Cancer Research UK, Lincoln's Inn Fields Laboratories, London WC 2A 3PX, United \\ Kingdom; ${ }^{4}$ Department of Genetics and Pathology, Rudbeck Laboratory, SE-751 85 Uppsala, Sweden; ${ }^{5}$ Wallenberg Laboratory \\ for Cardiovascular Research, Sahlgrenska Academy, Göteborg University, SE-413 45 Gothenburg, Sweden
}

During vascular development, endothelial platelet-derived growth factor B (PDGF-B) is critical for pericyte recruitment. Deletion of the conserved C-terminal heparin-binding motif impairs PDGF-BB retention and pericyte recruitment in vivo, suggesting a potential role for heparan sulfate (HS) in PDGF-BB function during vascular development. We studied the participation of HS chains in pericyte recruitment using two mouse models with altered HS biosynthesis. Reduction of $N$-sulfation due to deficiency in $N$-deacetylase/ $N$-sulfotransferase-1 attenuated PDGF-BB binding in vitro, and led to pericyte detachment and delayed pericyte migration in vivo. Reduced $N$-sulfation also impaired PDGF-BB signaling and directed cell migration, but not proliferation. In contrast, HS from glucuronyl C5-epimerase mutants, which is extensively $\mathrm{N}$ - and 6-O-sulfated, but lacks 2-O-sulfated L-iduronic acid residues, retained PDGF-BB in vitro, and pericyte recruitment in vivo was only transiently delayed. These observations were supported by in vitro characterization of the structural features in HS important for PDGF-BB binding. We conclude that pericyte recruitment requires HS with sufficiently extended and appropriately spaced $N$-sulfated domains to retain PDGF-BB and activate PDGF receptor $\beta$ (PDGFR $\beta$ ) signaling, whereas the detailed sequence of monosaccharide and sulfate residues does not appear to be important for this interaction.

[Keywords: PDGF-B; angiogenesis; heparan sulfate; pericyte; vascular development]

Supplemental material is available at http://www.genesdev.org.

Received June 21, 2006; revised version accepted December 5, 2006.

Tissue morphogenesis depends on cell-cell interactions, controlling directed cell migration proliferation, differentiation, and cell survival. Specificity is often regulated at the level of selective ligand-receptor interaction. However, the spatial distribution and local concentration of the ligand determine the range of the signal, and, as exemplified by morphogens of the hedgehog, TGF $\beta$,

\footnotetext{
${ }^{6}$ These authors contributed equally to this work.

Present addresses: ${ }^{7}$ Laboratory of Proteoglycan Signaling and Therapeutics, Hokkaido University, 5th floor Frontier Research Center for PostGenomic Science and Technology, Nishi 11-choume, Kita 21-jo, Kita-ku, Sapporo 001-0021, Japan; ${ }^{8}$ Molecular Toxicology, Safety Assessment, AstraZeneca AB, SE-151 85 Södertälje, Sweden.

${ }^{9}$ Corresponding author.

E-MAIL holger.gerhardt@cancer.org.uk; FAX 44-207-269-3417.

Article is online at http://www.genesdev.org/cgi/doi/10.1101/gad.398207.
}

and Wnt family members, also the nature of the signal. Indeed, spatial restriction defines the activities of most peptide growth factors and many secreted neural guidance molecules. In vascular development, peptide growth factors of the VEGF and platelet-derived growth factor (PDGF) families regulate the migration and proliferation of endothelial cells and supporting mural cells; i.e., pericytes (PC) and vascular smooth muscle cells (vSMC). The longitudinal migration and proliferation of vSMC/PC depend on paracrine signaling of endothelial derived PDGF-B to PDGF receptor- $\beta$ (PDGFR $\beta$ ) expressed on vSMC/PC (Lindahl et al. 1997; Hellström et al. 1999). PDGF-B is secreted as a homodimer (PDGF$\mathrm{BB})$, which signals by mediating dimerization of its receptor. Conditional inactivation of $P d g f-b$ in the endothelium demonstrated that endothelial cells are the 
main source of PDGF-BB required for SMC/PC recruitment (Enge et al. 2002; Bjarnegard et al. 2004). Exon 6 in the Pdgf- $b$ gene codes for a basic amino acid motif referred to as the retention motif. This sequence shows structural similarities with the heparan sulfate (HS)-interacting domain of VEGF-A and is thought to mediate binding to the cell surface or extracellular matrix (LaRochelle et al. 1991; Östman et al. 1991). The retention sequence of PDGF-B may be removed by proteolysis to generate a more diffusible protein. Mice with a homozygous deletion of the retention motif, Pdgf- $b^{\text {ret/ret }}$, have defective investment of PCs in the microvascular system, indicating that the retention properties of PDGF-BB are essential for proper vSMC/PC assembly and hence for a fully functional vasculature (Lindblom et al. 2003).

Surprisingly little is known about the extracellular components involved in PDGF-BB distribution and signaling in vivo. From studies in various organisms as well as in vitro systems, it has become clear that HS proteoglycans (HSPGs) mediate retention of many growth factors and morphogens (Lin 2004; Hacker et al. 2005). HS is generated as repeating units of $\mathrm{N}$-acetylglucosamine (GlcNAc) and glucuronic acid (GlcA) linked to core proteins at specific serine residues. The newly synthesized linear polysaccharide chain undergoes extensive modification: $N$-deacetylation/ $N$-sulfation of GlcNAc residues by $N$-deacetylase/ $N$-sulfotransferases (NDSTs), C5epimerization of GlcA to iduronic acid (IdoA) by a HS glucuronyl C5-epimerase (Hsepi, synonym Glce), and finally $\mathrm{O}$-sulfation at $\mathrm{C} 2$ of IdoA and, rarely, GlcA, C6 of GlcNAc and glucosamine $N$-sulfate (GlcNS), and C3 of GlcNS (or $N$-unsubstituted glucosamine) units (Esko and Lindahl 2001; Esko and Selleck 2002). The overall process is generally incomplete, such that the final HS products display domain-type arrangement of more or less modified saccharide regions. Partly due to the substrate specificities of the enzymes involved, IdoA and $O$-sulfate residues occur predominantly in $N$-sulfated domains created by NDST action. The distribution, extension, and modification level of such domains appear to be tightly regulated in a tissue/cell-specific fashion (Ledin et al. 2004), although the underlying regulatory mechanisms remain poorly understood. The negative charge contributed by carboxyl and sulfate groups is essential for interactions between HS and basic amino acid residues in proteins such as VEGF-A (Robinson et al. 2006) and PDGFs (Feyzi et al. 1997a). However, with a few notable exceptions, major questions concerning specificity and selectivity in HS-protein interactions remain unresolved (Esko and Lindahl 2001; Gallagher 2001; Kreuger et al. 2006). Key enzymes in polymer modification during HS biosynthesis are the NDSTs, which create the basis for all further modification of the chains in those domains that become $N$-sulfated (NS domains). There are four known isoforms, Ndst-1-4. Ndst-1 and Ndst-2 are both ubiquitously distributed during development as well as in adult mice, while Ndst-3 and Ndst-4 are mostly expressed during development (Ford-Perriss et al. 2002; Grobe et al. 2002; Yabe et al. 2005). Surprisingly, though, the only clear phenotype in mice deficient in NDST-2 is observed in mast cells of connective tissue (Forsberg et al. 1999|. Mice lacking NDST-1 have a more severe phenotype and die between embryonic day 14.5 (E14.5) and shortly after birth (Ringvall et al. 2000). The dramatically reduced HS sulfation in these mice results in brain malformation and skeletal defects (Grobe et al. 2002, 2005). These findings implicate the highly sulfated NS domains in growth factor-binding events, but do not differentiate between requirements for defined sequence versus overall charge density. Epimerization of GlcA to IdoA increases the flexibility of the sugar chain and is prerequisite to some of the further $O$-sulfation steps. Deletion of the Hsepi gene leads to formation of a HS analog that is highly $N$-sulfated, but devoid of IdoA units, thus with severely perturbed fine structure (Li et al. 2003). Comparison of phenotypes due to Ndst-1 or Hsepi knockout may therefore provide clues to qualify the dependence on saccharide structure.

The importance of HS for PDGF-BB retention in vascular development has not been directly demonstrated, but is indirectly inferred based on the HS-binding properties of the PDGF-BB retention motif (Lindblom et al. 2003). Here, we investigated PDGF-BB-dependent PC recruitment in the developing hindbrain of mouse mutants for Ndst-1, Hsepi, and Pdgf-bret. We combined these studies with in vitro analysis of the structural requirements of HS-domains for PDGF-BB binding, using HSrelated oligomer libraries and isolated HS from Ndst-1 and Hsepi mutants. Together, the data show an astonishing degree of correlation between in vitro binding of PDGF-BB to HS and in vivo PC recruitment/attachment. Moreover, they demonstrate that $N$ - and $O$-sulfation of HS are required for efficient PDGF-BB binding, whereas saccharide fine structure is of lesser importance. Cell culture assays provided corroborating direct evidence for reduced retention of PDGF-BB on cells deficient in HS and indicated that HS may contribute to PC recruitment by augmenting PDGFR $\beta$ signaling and directed cell migration toward PDGF-BB. This is to our knowledge the first in vivo proof that interaction of PDGF-BB with sulfated HS regions is essential for PC recruitment in vascular development.

\section{Results}

\section{Defective PC recruitment in HS-deficient mice}

Hindbrain whole-mounts from E11.5 Ndst-1/- mice and control littermate embryos were double-labeled with the isolectin-B4 and an antibody recognizing the chondroitin sulfate proteoglycan NG2 to visualize endothelial cells and PCs, respectively. Analysis of flat-mounted wildtype hindbrains revealed a close association between PCs and the endothelium, including the tip cells at the outermost growing front of the vascular plexus (Fig. 1A). In Ndst-1-1- embryos, however, PCs frequently failed to reach the growing vascular front (Fig. 1B). In comparison with $N d s t-1^{-/-}$mice, the vascular defects of $P d g f-b^{\text {ret/ret }}$ mice were more severe, with an even broader region of 
Abramsson et al.

Figure 1. Delayed PC coverage of the vasculature lacking NDST-1 or the PDGF-B retention motif. Staining of hindbrain endothelium and associated PCs from wild-type $(A), N d s t-1^{-/-}(B)$, and Pdgf- $b^{\text {ret }}$ ${ }_{\text {ret }}(C)$ embryos with isolectin (red) and NG2 (green). Wild-type PCs cover the endothelium up to the sprouting front. In contrast, large parts of sprouting vessels remain uncovered in the $N d s t-1^{-/-}$and

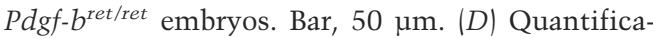
tion of the total length from the sprouting endothelial tip to the first PC. $(E)$ Illustration of interindividual variation.
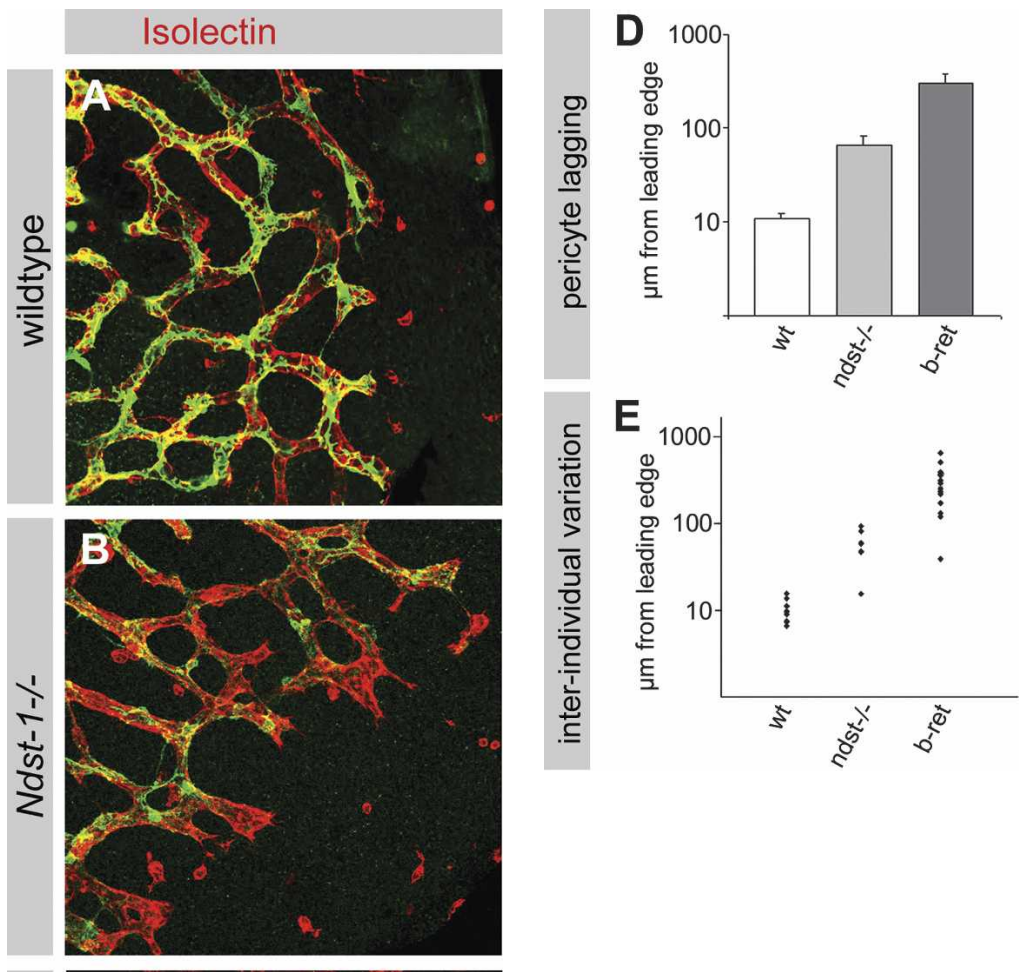

the newly formed plexus devoid of PCs (Fig. 1C,D). Quantification of the distance from the growing endothelial edge to the closest PCs revealed that PCs in control animals occurred $10 \pm 1.5 \mu \mathrm{m}(n=5)$ from the leading edge, whereas the distance was $70 \pm 15 \mu \mathrm{m}(n=4)$ and $300 \pm 74 \mu \mathrm{m}(n=4)$ in Ndst- $1^{-/-}$and Pdgf- $b^{\text {ret/ret }} \mathrm{mu}-$ tants, respectively (Fig. 1D). Observations based on a large number of embryos showed that $N d s t-1^{-/-}$mice varied in the extent of PC deficiency, ranging from severely affected embryos, where the peripheral compartment of the vascular plexus was completely devoid of PCs, to embryos with an almost normal recruitment of PCs to the brain vasculature (Fig. 1E).

\section{Defective PC coverage and attachment in $\mathrm{Ndst}^{-1-}$} and Pdgf- $\mathrm{b}^{\mathrm{ret} / \mathrm{ret}}$ mutants

In mature capillaries, PCs are tightly wrapped around the endothelium, with interdigitating processes, occasionally stretching over considerable distance. The brain vas- culature is particularly rich in PCs, which almost completely cover the ablumenal surface of the endothelium. Improved availability of PC markers has now clarified that PCs, contrary to previous notions, are very rapidly recruited to new vascular sprouts (Gerhardt and Betsholtz 2003). Here, we found a higher PC coverage at the midline (Fig. 2A,C,E) than in the periphery (Fig. 2B,D,F) in hindbrains of all genotypes, most likely reflecting the earlier development of the vascular plexus at the midline. Thus, although PCs are initially recruited to the growing sprout, the full coverage with PCs is only achieved during subsequent vascular maturation. We therefore analyzed confocal images at the periphery $(\mathrm{p}$ in Fig. 2G) and midline ( $\mathrm{m}$ in Fig. 2G) of the growing hindbrain vasculature to quantify the proportion of PC-endothelial apposition (PC coverage) in relation to the total area of the endothelium. At the midline of both wild type $(n=4)$ and Ndst-1-1- mutants $(n=6), 60 \%$ of the capillary area was covered with PCs (Fig. $2 \mathrm{H}$, white and light-gray bars, respectively). In Pdgf- $b^{\text {ret/ret }}$ mutants, 

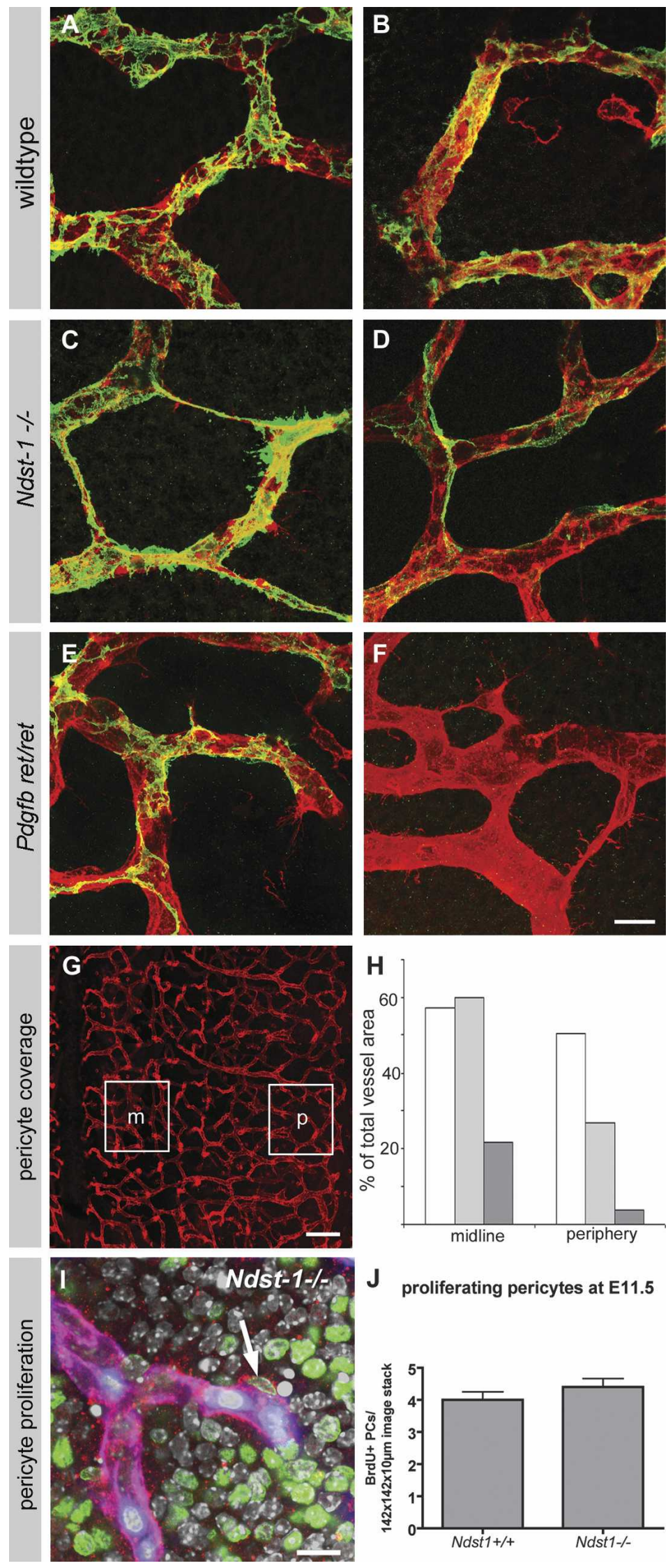

$\mathbf{J}$ proliferating pericytes at E11.5

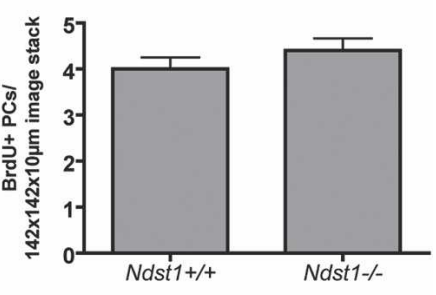

Figure 2. Reduced PC coverage of endothelium in Ndst$1^{-1-}$ and $P d g f-b^{\text {ret/ret }}$ hindbrain. Comparison of PC coverage at the midline $(A, C, E)$ and periphery $(B, D, F)$ of hindbrains of wild-type $(A, B), N d s t-1^{-1-}(C, D)$, and Pdgf$b^{\text {ret/ret }}(E, F)$ embryos stained with isolectin (red) and NG2 (green). $(G)$ Illustration of the hindbrain areas representing midline $(\mathrm{m})$ and periphery $(\mathrm{p})$. Bars: $A-E, 20 \mu \mathrm{m} ; G$; $100 \mu \mathrm{m}$. (H) Relative proportion of endothelial staining overlapping with PC staining in percent of total vessel area (see also Materials and Methods; Abramsson et al. 2003) at the midline and periphery of wild-type (white bars), Ndst-1-1- (light-gray bars), and Pdgf-bet/ret (dark-

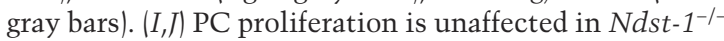
hindbrains. (I) Illustration of Ndst-1-/- hindbrain sample labeled for PDGFR $\beta$ (red), isolectin (blue-purple), BrdU (after 2-h pulse; green), and DAPI (gray-white). The arrow points to proliferating PC with PDGFR $\beta$ labeling on the cell surface. Bar, $10 \mu \mathrm{m}$. (J) Quantification of BrdU-positive PC (see Materials and Methods for details; see Supplementary Fig. 1 for illustration of confocal stacks analyzed for quantification). 
only $34 \%(n=4)$ of the endothelium in the same area was covered (Fig. $2 \mathrm{H}$, dark-gray bar). In the periphery of the hindbrain, PC coverage in wild-type embryos was $52 \%$ (Fig. 2H, white bar). At this site, the endothelium of $N d s t-1^{-1-}$ and Pdgf- $b^{\text {ret/ret }}$ mice was only covered with PCs to $35 \%$ and $4 \%$, respectively (Fig. $2 \mathrm{H}$, light-gray and dark-gray bars, respectively). Thus, the initial recruitment phase seems to be more severely affected by structural deficiency of HS or lack of the PDGF-B retention motif. PDGF-BB is most strongly produced by the leading tip cells and thus acts to direct migration of PCs along the nascent vascular sprout (Gerhardt and Betsholtz 2003). However, PDGF-BB is also required for PC proliferation (Hellström et al. 1999). To determine the cause of deficient PC recruitment in Ndst-1-1- hindbrains, we studied PC proliferation by BrdU incorporation using confocal microscopy on hindbrains labeled with BrdU, PDGFR $\beta$, Isolectin-B4, and DAPI. BrdU-positive nuclei juxtaposed to Isolectin-B4-labeled endothelium and surrounded by PDGFR $\beta$ labeling were scored as proliferating PCs. We found prominent proliferation of PCs in Ndst-1 $1^{-/}$and wild-type littermates with no differences between the genotypes (Fig. 2I,J), indicating that the reduced PC coverage in $N d s t-1^{-/-}$embryos is not caused by deficient expansion of the PC population through proliferation.

In addition to the delayed spreading and establishment of a continuous cover, we observed that in $N d s t-1^{-/-}$embryos, pericytic processes frequently stretched away from the endothelium (Fig. 3B). This was in contrast to the very tight endothelial-PC association seen in the wild-type embryos (Fig. 3A). This conspicuous appearance was reminiscent of earlier observations in the retina or in tumors in $P d g f-b^{\text {ret/ret }}$ mice (Abramsson et al. 2003; Lindblom et al. 2003). Here, we found numerous PC protrusions lacking endothelial contact also in the hindbrain of the Pdgf- $b^{\text {ret/ret }}$ mice (Fig. 3C). Thus, PCs in the CNS of Pdgf- $b^{\text {ret/ret }}$ and Ndst-1-1- mice seemed strikingly similar in being more loosely attached to the capillaries. Together, the similarities shared between the Pdgf- $b^{\text {ret/ret }}$ and Ndst-1-1- phenotypes suggest that HS modifications catalyzed by NDST-1 may be crucial for PDGF-BB retention.

\section{Sulfated HS is concentrated on the vascular endothelium of the hindbrain}

In situ hybridization studies and RT-PCR (Yabe et al. 2005) as well as immunohistochemical detection (Grobe et al. 2005) have previously shown that Ndst-1 is expressed in the developing brain. To investigate the localization of HS in the hindbrain, the HepSS-1 antibody was used. The epitope recognized by this antibody is known to contain extended sequences of $N$-sulfated disaccharide units (van den Born et al. 2005). Confocal images of wild-type hindbrains labeled with the HepSS-1 antibody revealed most abundant HS deposition on the abluminal endothelial surface (Fig. 4A-C). The same was true for vessels in the Pdgf-b $b^{\text {ret/ret }}$ mutants (Fig. 4G-I). In contrast, Ndst-1-deficient embryos almost completely
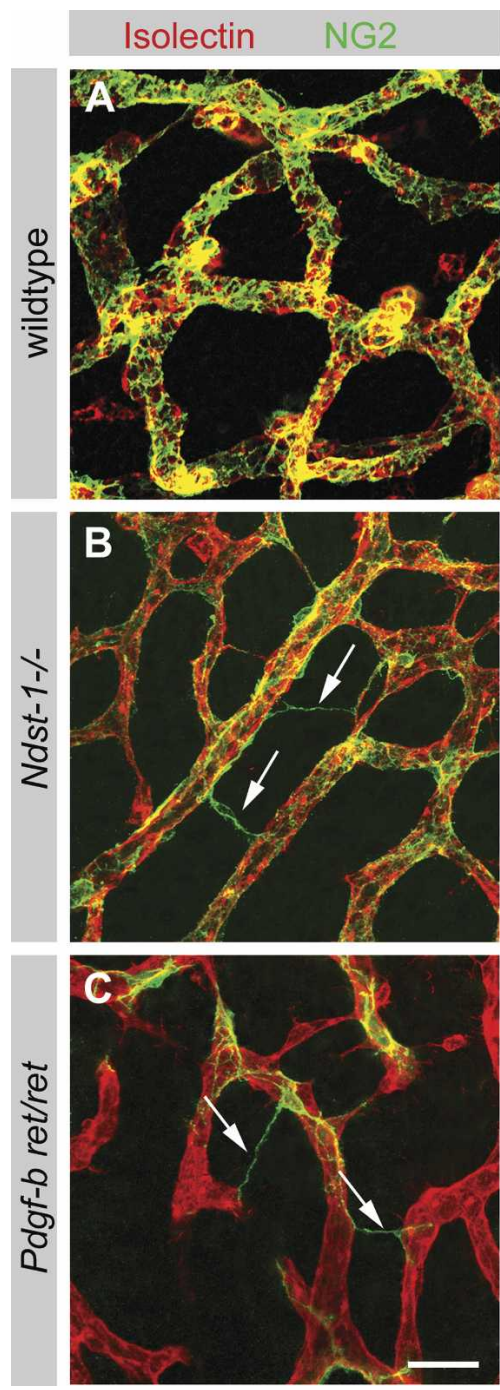

Figure 3. Defective PC association to endothelium in Ndst$1^{-1-}$ and Pdgf- $b^{\text {ret/ret }}$ embryos. (A) High-resolution images of wild-type hindbrain stained with isolectin (red) and NG2 (green) revealed a tight and circumferential cover of PCs. In hindbrains of $N d s t-1^{-/-}(B)$ and $P d g f-b^{\text {ret/ret }}(C)$ mutants, pericytic processes were frequently found to stretch out into the surrounding tissue or to make contact with neighboring vessels (arrows in $B, C$ ). Bar, $40 \mu \mathrm{m}$.

lacked endothelial HepSS-1 labeling (Fig. 4D-F). These results suggested that NDST-1 is required for endothelial HS-sulfation and not compensated for by any other NDST isoenzyme. If the endothelial HS-sulfation in turn were critical for PDGF-BB binding, it would explain the defective PC recruitment and coverage in $\mathrm{Ndst-1^{-/- }}$ mice. We therefore decided to investigate the nature of PDGF-BB binding to HS in more detail.

\section{PDGF-BB homodimers bind to HS SAS domains}

What is the minimal size of a HS domain capable of binding PDGF-BB under physiologic ionic conditions? 


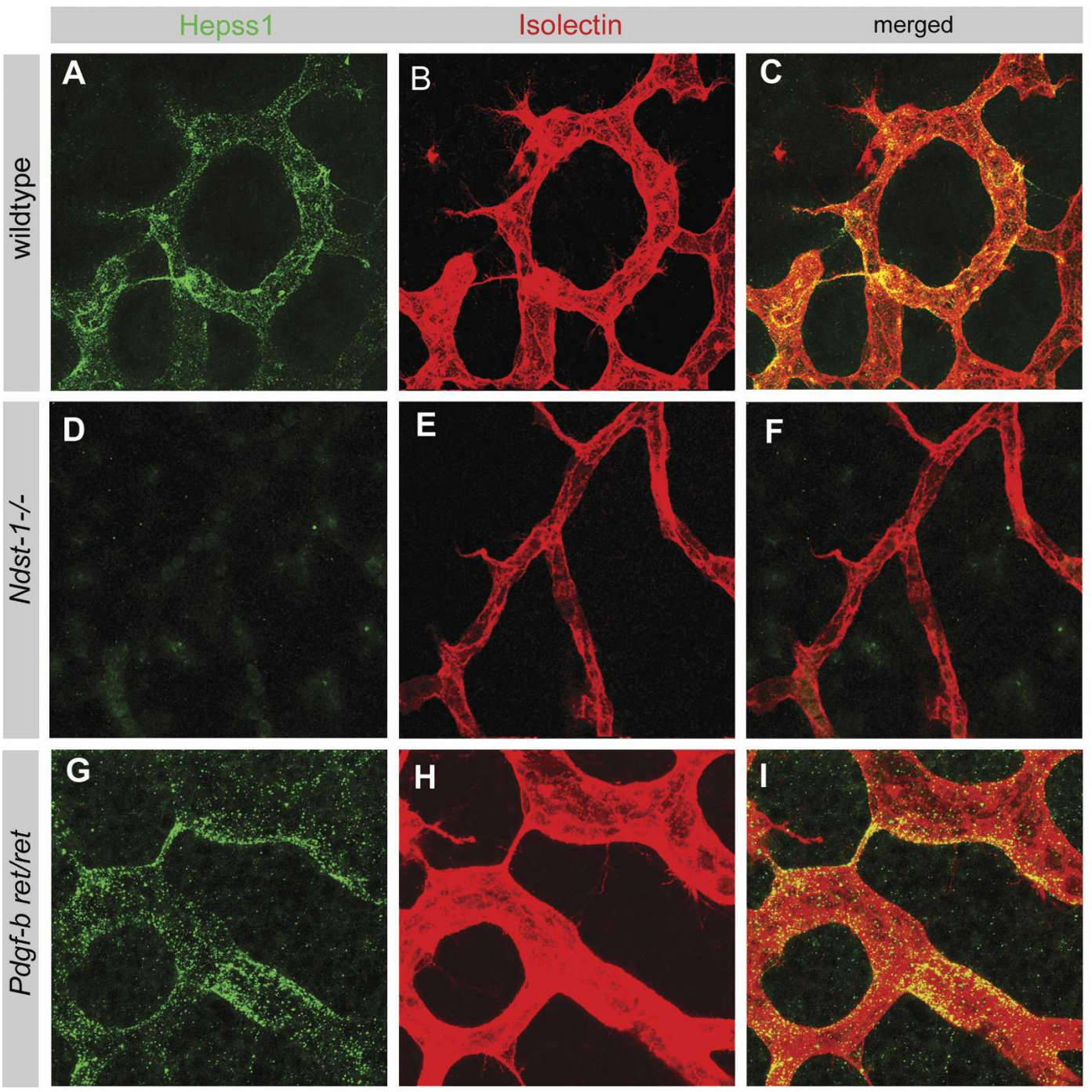

Figure 4. HS localizes to vascular structures in developing hindbrain. HS distribution in hindbrain was visualized using the HepSS-1 antibody (green), while isolectin (red) was used as an endothelial marker. In wild-type $(A-C)$ and $P d g f-b^{\text {ret/ret }}(G-I)$ embryos, HS overlapped with the vasculature. $(D-F)$ The HS staining was absent or highly reduced in hindbrains of $N d s t-1^{-/-}$mutants. Bar, $40 \mu \mathrm{m}$.

To answer this question, size-defined heparin oligosaccharides, essentially fully $N$ - and $O$-sulfated, were applied to affinity chromatography on immobilized PDGFBB dimer, and eluted using a stepwise salt gradient. The apparent affinity of PDGF-BB for heparin oligosaccharides increased with the length of the fragments (Fig. 5A). Heparin 4-mers bound very weakly, whereas 6-mers and 8-mers were retained on the column to a higher degree and with increasing affinity. Oligosaccharides of 12-mer and larger size showed maximal binding. These results suggest that the smaller oligomers interact primarily with PDGF-B monomers, whereas the actual binding region for a PDGF-BB dimer resides within a 12-mer sequence. These binding characteristics are similar to those previously demonstrated for PDGF-AA (Lustig et al. 1996; Feyzi et al. 1997a). Contiguous NS domains of 12-mer size are rare in HS. On the other hand, previous studies have shown that binding sites for oligomeric
(Lortat-Jacob et al. 1995; Stringer and Gallagher 1997; Spillmann et al. 1998) as well as monomeric protein ligands (Kreuger et al. 2002) may be composed of shorter NS domains separated by one or more $N$-acetylated disaccharide units ("SAS domains"). Fragments containing such domains were generated by limited cleavage of HS (from pig intestinal mucosa) at $\mathrm{N}$-sulfated glucosamine residues (reaction with $\mathrm{HNO}_{2}$ at $\mathrm{pH}$ 1.5), and radiolabeled by subsequent reduction with $\mathrm{NaB}^{3} \mathrm{H}_{4}$ (see Materials and Methods). The products were separated by gel chromatography, and size-defined species were individually tested for binding to PDGF-BB. SAS fragments of $\geq 10$-mer size showed appreciable binding (Fig. 5B). To further characterize the PDGF-BB-binding SAS fragments, a pool of $\sim 8$-mers to 18 -mers was applied to the PDGF-BB column, and separated into flow-through (eluted with $50 \mathrm{mM}$ Tris- $\mathrm{HCl}$ at $\mathrm{pH}$ 7.4), a weakly binding (eluted with $0.25 \mathrm{M} \mathrm{NaCl}$ ), and a strongly binding 


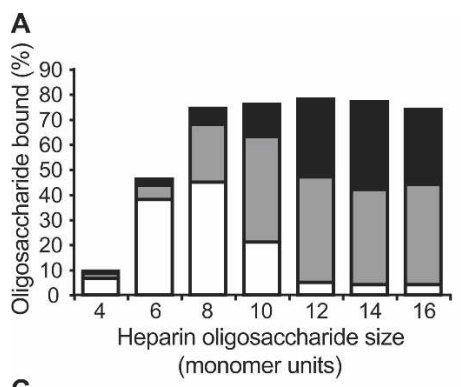

C
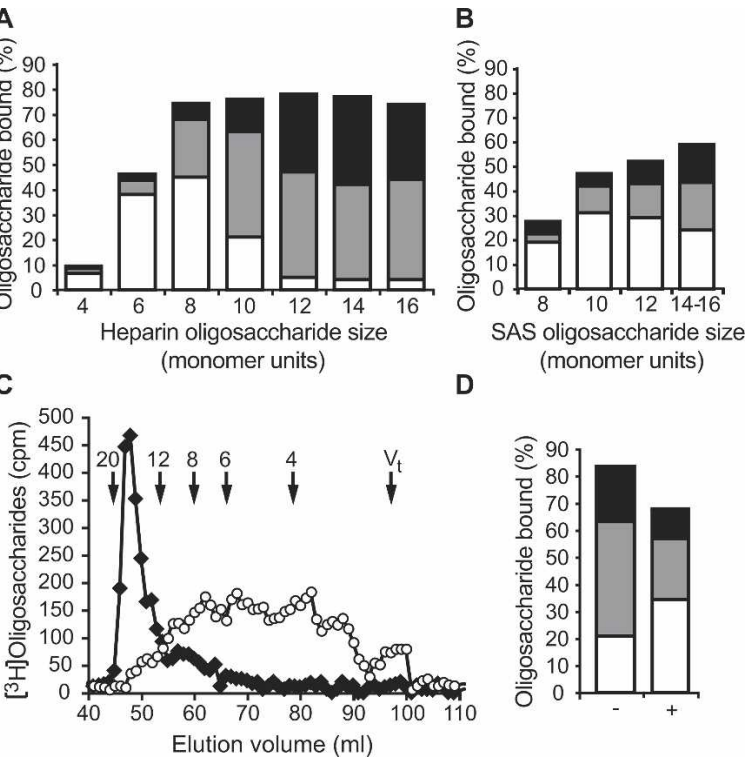

Figure 5. Binding of heparin and HS oligosaccharides to PDGFBB. (A) The size of heparin oligosaccharides able to bind to PDGF-BB. Size-defined ${ }^{3} \mathrm{H}$-end-labeled fragments were allowed to bind to the PDGF-BB affinity column and were then eluted as described in Materials and Methods. The amounts of radioactivity in fractions eluted with $0.15 \mathrm{M}$ (white bars), $0.2 \mathrm{M}$ (gray bars), and 0.4 $\mathrm{M}$ (black bars) $\mathrm{NaCl}$ were determined and plotted as the percent of total radioactivity applied. Not shown is material unretarded upon application in $50 \mathrm{mM}$ Tris- $\mathrm{HCl}$ (pH 7.4). $(B)$ The same type of affinity separation was performed with SAS oligosaccharides isolated by partial cleavage of HS chains. $(C)$ Affinity-purified SAS fragments ( 8-18-mer) eluted with $0.4 \mathrm{M}$ $\mathrm{NaCl}$ from PDGF-BB were separated on a sizing column before (filled symbols) and after (open symbols) cleavage at chemically $\mathrm{N}$-deacetylated glucosamine units as described in Materials and Methods. Size-defined, standard heparin oligosaccharides run on the same column are indicated with arrows. $(D)$ The same SAS fragments were also reapplied to PDGF-affinity chromatography before (indicated with -) and after (marked with + ) selective cleavage at $N$-deacetylated glucosamine units. The amounts of radioactivity in each effluent fraction were determined and plotted as the percent of total radioactivity as described in $A$.

(eluted with $0.45 \mathrm{M} \mathrm{NaCl}$ ) fraction (data not shown). The latter fraction ranged from 12 -mers to 18 -mers, as demonstrated by gel chromatography (Fig. 5C), whereas weakly binding species were $\leq 12$-mers (data not shown). The SAS character of the PDGF-BB-binding oligosaccharides was verified by $N$-deacetylation followed by deaminative cleavage of $N$-unsubstituted glucosamine units. The degradation induced by this treatment was indicative of internal $N$-acetylated disaccharide units in the intact oligosaccharides (Fig. 5C). The terminally radiolabeled fragments thus obtained showed appreciable loss of affinity for PDGF-BB (Fig. 5D), suggesting a bridging function for the GlcNAc residues. A proportion of the fragmented oligosaccharides still retained affinity for the immobilized growth factor, pointing to occurrence also of longer, contiguous $N$-sulfated sequences within the SAS preparation (Fig. 5D).

\section{PDGF-BB affinity increases with overall O-sulfation} of $H S$

Biosynthesis of HS is concluded by 2-O-, 6-O-, and, more rarely, 3-O-sulfation of previously $\mathrm{N}$-sulfated intermediary polysaccharide (Esko and Lindahl 2001), leading to increased overall negative charge as well as sequence heterogeneity. To assess the role of $\mathrm{O}$-sulfation in PDGF-BB binding, oligosaccharide libraries were generated by chemo-enzymatic modification of heparin (see Materials and Methods). Pools of $N$-sulfated 12-mers, each with a given number (from one to five) of 2-O-sulfate groups, were individually subjected to enzymatic 6-O-sulfation. Anion-exchange HPLC patterns of the various pools before and after 6-O-sulfation revealed the number of 2-O-sulfate groups at start and the number (zero to four) of added 6-O-sulfates, respectively (Fig. 6AE). Affinity chromatography on PDGF-BB showed a consistent increase in affinity with increasing degree of 2-Osulfation, even in the absence of 6-O-sulfation, and further increased binding after 6-O-sulfation (Fig. 6F-J). These results show that binding of HS-related saccharides to PDGF-BB depends on overall degree of sulfation, without any apparent requirement for specific sequence.

Ndst-1 ${ }^{-/-}$and $\mathrm{Hsepi}^{-/-}$mice-correlation of HS structure, PDGF-BB binding, and vascular phenotype

The in vitro binding experiments with radiolabeled heparin oligosaccharides and SAS fragments isolated from authentic HS pointed to the importance of sufficiently

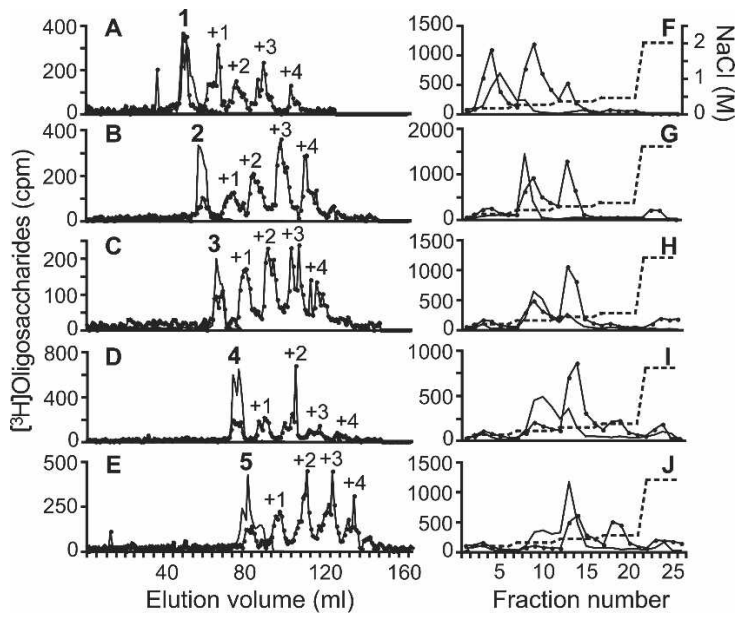

Figure 6. Assessment of $O$-sulfation required for optimal binding. An oligosaccharide library was made from ${ }^{3} \mathrm{H}$-radiolabeled, 6-O-desulfated heparin dodecasaccharides that were separated according to their number of 2-O-sulfate groups (one to five 2-O-sulfate groups as indicated with bold numbers above black lines in $A-E)$ and then separately subjected to enzymatic 6-Osulfation as described in Materials and Methods. The modified structures (containing additional 6-O-sulfate groups as indicated, +1 to +4 ) were reapplied to the anion-exchange column (filled symbols in $A-E$ ) as described. The nonmodified structures (black lines) and the pools of biosynthetically modified dodecasaccharides (filled symbols) were subjected to affinity chromatography using a stepwise salt gradient as shown in F-J. 
extended, or appropriately spaced, NS domains in HS interacting with PDGF-BB. The deficient PC recruitment in Ndst-1-/- embryos could thus be caused by inadequate interaction of PDGF-BB with the poorly $N$-sulfated HS in the vasculature. Previous structural analysis showed that $N$-sulfation of $N d s t-1^{-/-}$HS was drastically reduced compared with wild-type HS; notably, IdoA, 2-O-sulfate, and 6-O-sulfate residues were all present, albeit in reduced quantity (Ringvall et al. 2000; Ledin et al. 2004). To directly assess the effects of this structural change on PDGF-BB binding, HS isolated from $\mathrm{Ndst-1^{-/- }}$ embryos was radiolabeled by $N$-deacetylation and re- $N$ $\left[{ }^{3} \mathrm{H}\right]$ acetylation and was then applied to affinity chromatography on a PDGF-BB column. Whereas the corresponding wild-type HS was largely bound to the growth factor under physiological ionic conditions (Fig. 7A), only a minor fraction of the Ndst-1-null HS was retained (Fig. 7C).

HS synthesized by Hsepi-/- mice differs drastically in structure from both the corresponding wild-type and $N d s t-1^{-/-}$species, in that $N$-sulfation is more extended than in wild-type (and Ndst-1-1-) HS, whereas IdoA and IdoA-2-O-sulfate residues are lacking. Instead, glucosamine 6-O-sulfation is increased, such that the overall level of sulfation is about the same as in wild-type HS (Li et al. 2003). Affinity chromatography of Hsepi-l- embryonic $N-\left[{ }^{3} \mathrm{H}\right]$ acetyl-labeled HS showed a fraction of PDGFBB-binding material, albeit somewhat reduced compared with the wild-type sample (Fig. 7B). To analyze PDGF-BB retention in a cellular context, we transfected mouse embryonic fibroblasts (MEF) from $N d s t-1^{+/+}, \mathrm{Ndst}-1^{-/-}$, $\mathrm{Hsepi}^{+/+}$, and $\mathrm{Hsepi}^{-/-}$embryos with human full-length

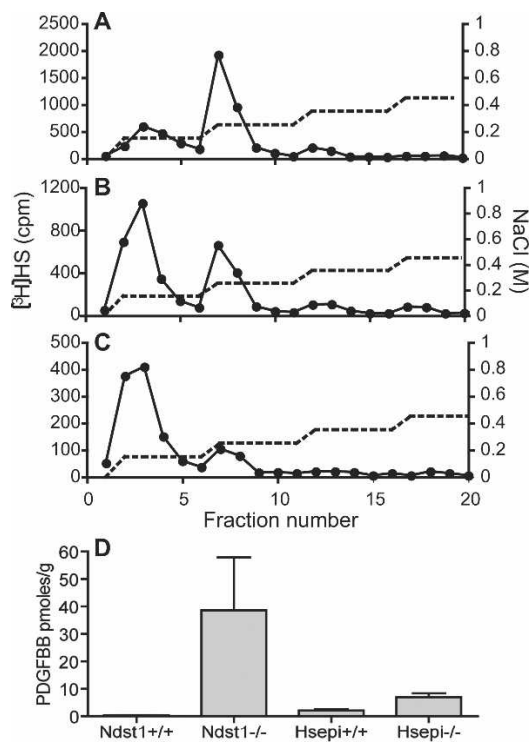

Figure 7. PDGF-BB binding of HS isolated from genetically modified mouse embryos. $N-\left[{ }^{3} \mathrm{H}\right]$ acetyl-labeled HS from wildtype $(A)$, Hsepi $^{-/-}(B)$, and Ndst-1 ${ }^{-/-}(C)$ embryos was affinityseparated on immobilized PDGF-BB, using a stepwise salt gradient as indicated. $(D)$ Three proximity ligation assay measuring PDGF-BB in medium of transfected MEFs isolated from Ndst-

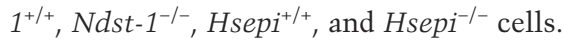

PDGF-BB and quantified PDGF-BB in cell lysates and medium by triple proximity ligation technique (Schallmeiner et al. 2007). We failed to detect significant amounts of PDGF-BB in the medium of $N d s t-1^{+/+}$and $\mathrm{Hsepi}^{+/+}$cells. However, Ndst-1-/- cells, and to a much lesser extent $\mathrm{Hsepi}^{-/-}$cells, accumulated PDGF-BB in the medium (Fig. 7D). Thus, both isolated endogenous HS from $N d s t-1^{-/-}$embryos and $N d s t-1^{-/-}$cells are deficient in PDGF-BB retention. However, C5-epimerization and subsequent modifications of HS appear to be of lesser importance for PDGF-BB retention.

We analyzed PC recruitment and coverage in $\mathrm{Hsepi}^{-/-}$ embryos to test the in vivo relevance of these findings. At E12.5, we found no sign of PC detachment or reduced coverage (data not shown). However, close scrutiny of the first plexus developing at day 10.5 revealed some delay in PC recruitment in the hindbrains of $\mathrm{Hsepi}^{-/-}$ embryos (Fig. 8A-H,M). Already at day 11.5, the coverage had normalized, and no sustained deficiency could be detected (Fig. 8I-L). Thus, the lack of C5-epimerase-dependent HS modification slightly reduced PDGF-BB binding in vitro and delayed PC recruitment in vivo. However, unlike $N$-sulfation, C5-epimerization appears not to be critical for PDGF-BB binding and PC recruitment in vascular development.

\section{Ndst-1 $1^{-/}$cells show signaling defects and reduced migration toward PDGF-BB}

The proliferation assay in vivo indicated that $N$-sulfated HS is dispensable for PC proliferation, but may affect directional PC migration during PC recruitment. Since MEFs express the PDGFR $\beta$ and can be recruited to nascent vessels by PDGF-BB (Abramsson et al. 2003), we used MEFs to test whether NDST-1 and HSEPI activity affect cell migration toward PDGF-BB. Immunofluoresence labeling (Fig. 9A-D) and Western blot analysis (data not shown) confirmed the expression of PDGFR $\beta$ in unstimulated MEFs of all genotypes. We used a modified Boyden chamber assay to assess migration of MEFs toward $20 \mathrm{ng} / \mathrm{mL}$ mouse PDGF-BB in medium added to the bottom chamber. Surprisingly, Ndst-1-1- cells migrated through the 3 - $\mu \mathrm{m}$ pores also in the unstimulated condition. However, the PDGF-BB-dependent relative increase in directed migration was strongly reduced in $\mathrm{Ndst}^{-/-}$ cells (ratio of stimulated migration/unstimulated $=2.4$ ) compared with wild-type ( 7) and $\mathrm{Hsepi}^{-/-}$cells (5.9) (Fig. 9E), suggesting that $N$-sulfated $\mathrm{HS}$ is important for PDGF-BB-induced chemotaxis. We therefore asked whether PDGFR $\beta$ activation and downstream signaling

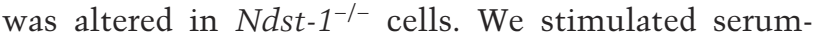
starved MEF cells for $10 \mathrm{~min}$ with $100 \mathrm{ng} / \mathrm{mL}$ PDGF-BB and investigated PDGFR $\beta$ phosphorylation as well as phosphorylation of SHP2, Akt, Erk1, and Erk2 MAPK. All cells showed phosphorylation of PDGFR $\beta$ upon PDGF-BB stimulation. However, $N d s t-1^{-/-}$cells displayed some PDGFR $\beta$ phosphorylation and phospho-Akt also under unstimulated conditions, with very little further increase in Akt phosphorylation upon PDGF-BB stimulation. Furthermore, Erk1 and Erk2 MAPK phos- 


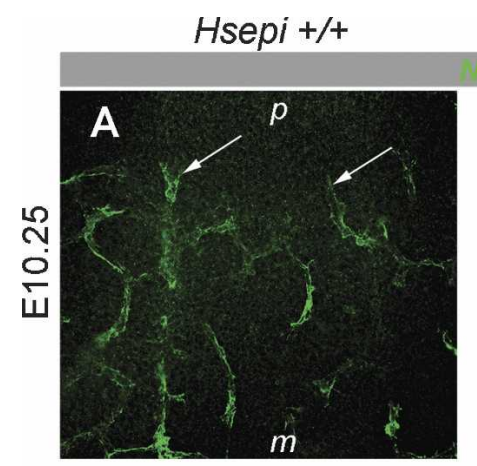

Hsepi -/-
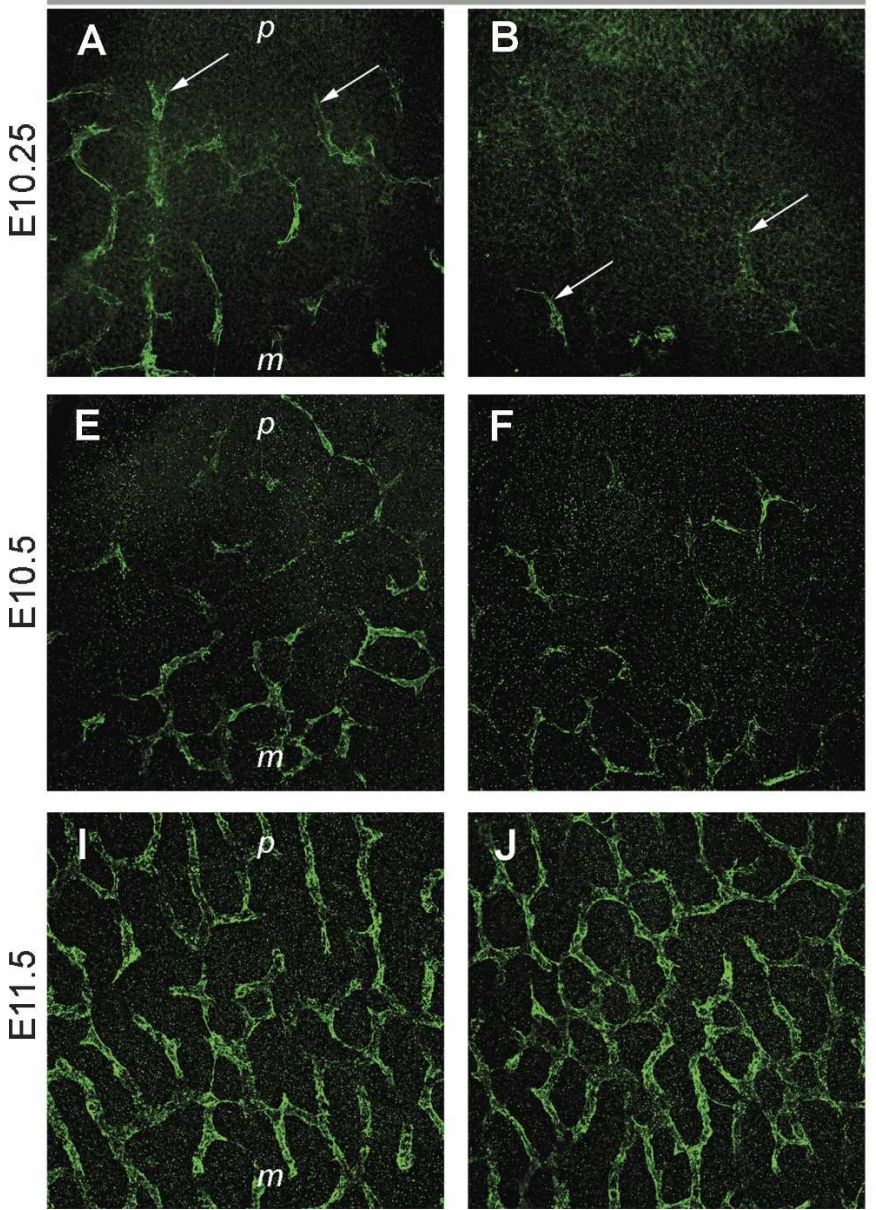
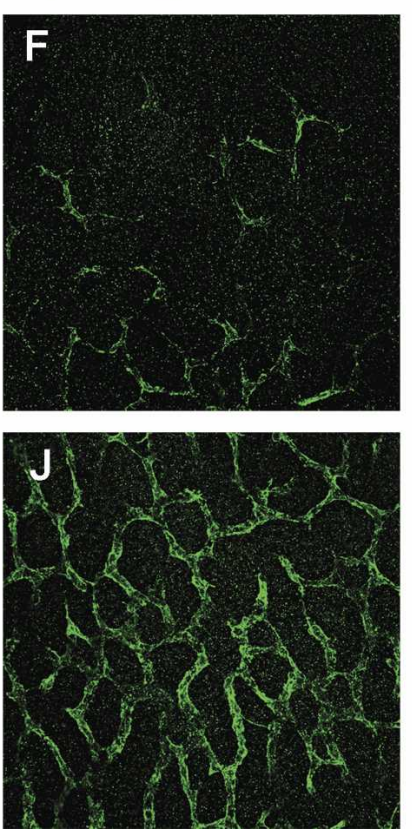

Hsepi $+/+$
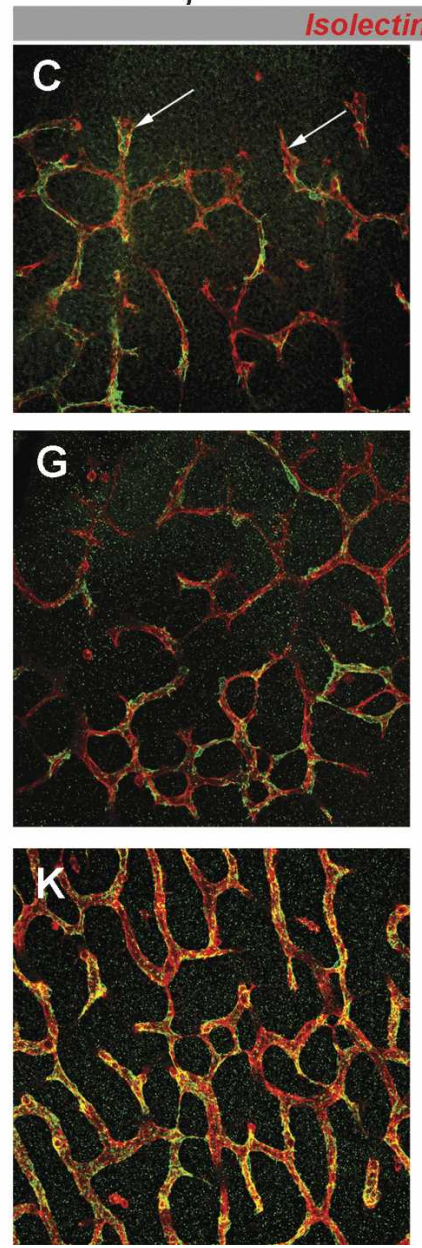

Hsepi -/-
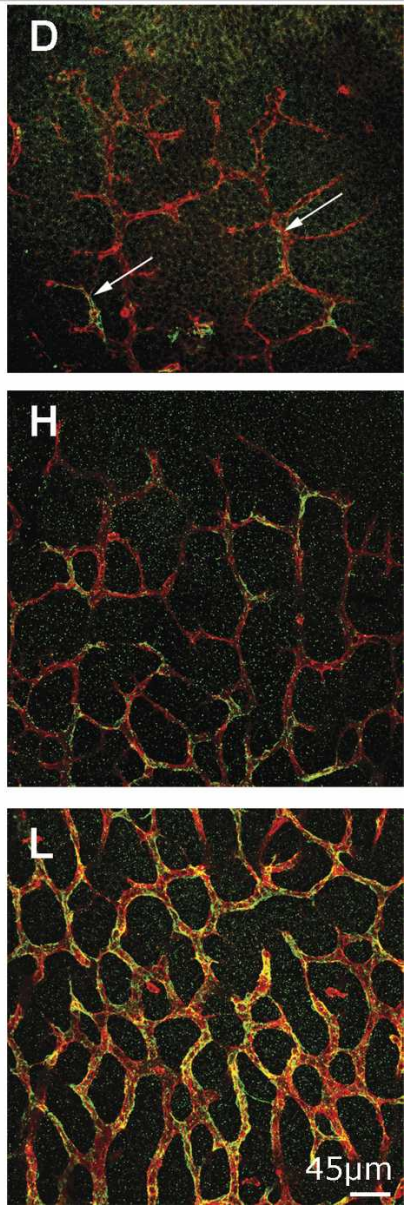

M Pericyte recruitment E10.5 hindbrain periphery

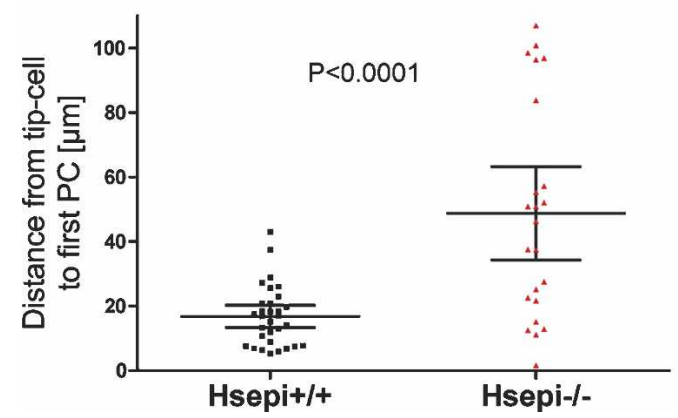

Figure 8. Transiently delayed PC recruitment in Hsepi-deficient mice. (A-D) At E10.25, PCs (arrows) stained for NG2 (green) were already abundant on hindbrain vessels (isolectin staining, red) in wild-type embryos $(A, C)$ both near the midline $(\mathrm{m})$ and near the avascular periphery (p). (B,D) In Hsepi-null embryos, PCs (arrows) were only sparse on vessels closest to the midline and absent in the periphery. $(E-H)$ At E10.5, PC recruitment was still slightly delayed in Hsepi-null embryos compared with wild-type littermates (quantified in $M$ ). $(I-L)$ By E11.5, PC recruitment was equally advanced in wild-type and Hsepi-null hindbrains (cf. $I$ and $I$, and $K$ and $L)$. (M) Quantification of the distance from the growing vascular front in the periphery to the first pericytic process at this stage indicated significantly delayed longitudinal recruitment in Hsepi-null embryos (wild type, $16.8 \pm 9.3 \mu \mathrm{m}_{;} \mathrm{Hsepi}^{-/-}, 48.7 \pm 33.4 \mu \mathrm{m}$; $n=63$ and 74, respectively; four hindbrains each; $p<0.001$ ).

phorylation was significantly reduced compared with both wild-type and $\mathrm{Hsepi}^{-/-}$cells (Fig. 9F). Together, these data suggest that whereas $\mathrm{N}$-sulfated HS domains are required in PDGF-BB signaling and directed migration toward PDGF-BB, the fine structure of such domains is of lesser importance. 

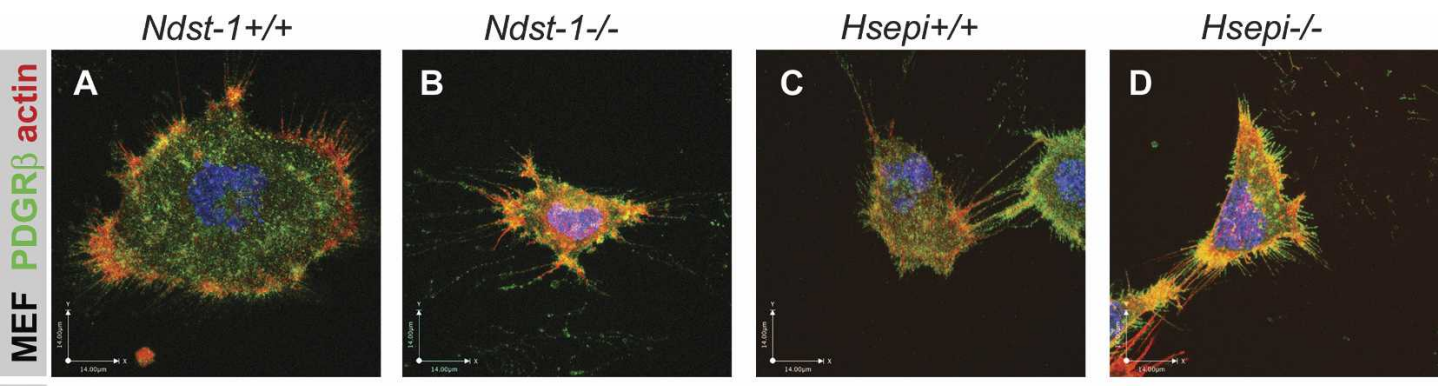

E

\section{$\mathbf{F}$}
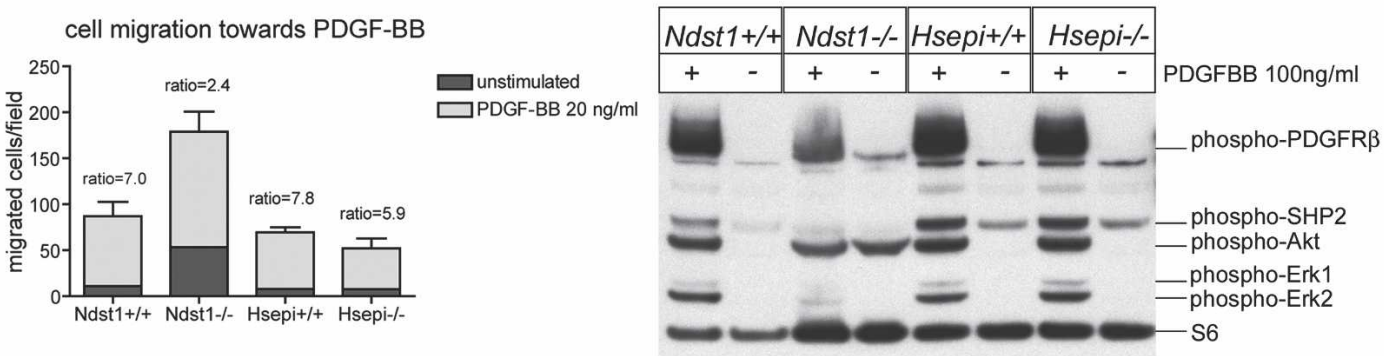

G
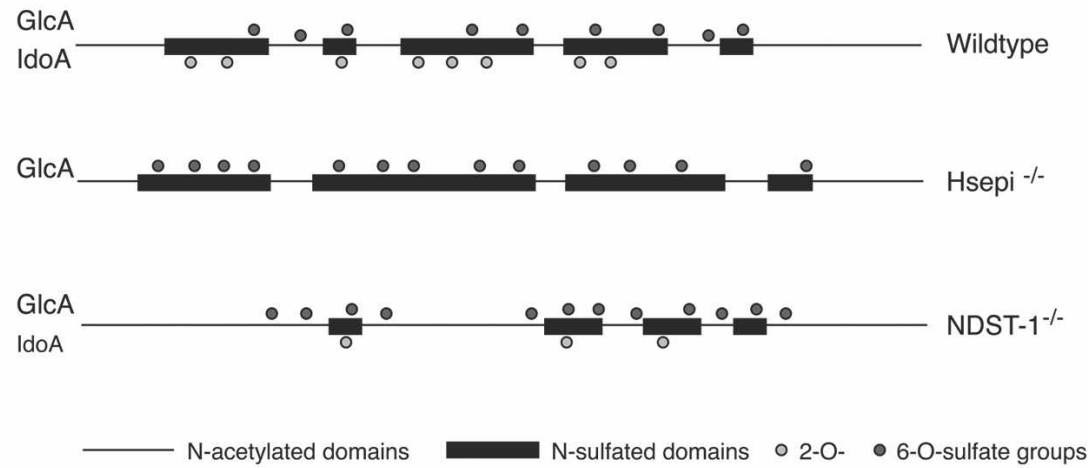

H

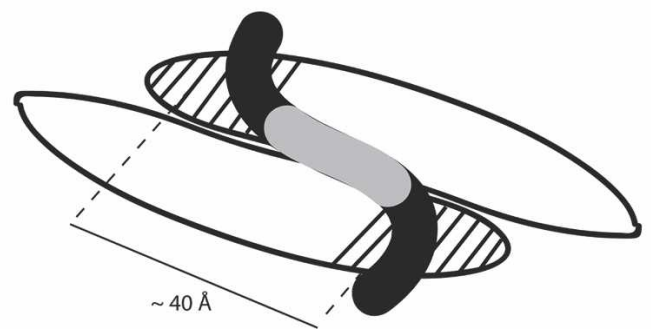

Figure 9. Ndst-1 $1^{-1-}$ MEF cells are deficient in PDGF-BB signaling and chemotaxis. $(A-D)$ Representative images of wild-type and HS mutant MEF cells expressing PDGR $\beta$ (green; counterlabeling for actin, red, and nuclei, DAPI, blue). (E) Quantification of a modified Boyden chamber chemotaxis assay using $20 \mathrm{ng} / \mathrm{mL}$ PDGF-BB as chemoattractant $(24 \mathrm{~h})$ in the bottom chamber. Control medium without PDGF-BB was used to assess baseline migration (unstimulated, dark gray). Note that although all cells migrated toward PDGF-BB (light-gray bars), the ratio of unstimulated/stimulated migration was reduced from $\sim 7$ in wild-type to 2.4 in $N d s t-1^{-/-}$cells. (F) Wild-type and $\mathrm{Hsepi}^{-/-}$MEF cells stimulated for $10 \mathrm{~min}$ with $100 \mathrm{ng} / \mathrm{mL}$ PDGF-BB show similar phosphorylation of PDGFR $\beta$, SHP-2, Akt, Erk1, and Erk2. However, Ndst-1-1- cells show reduced phosphorylation of PDGFR $\beta$, SHP-1, Erk1, and Erk2, and very little if any additional phosphorylation of Akt. Ribosomal protein S6 served as loading control. $(G, H)$ Schematic model of mutated HS structures $(G)$ and of HS-PDGF-BB interaction $(H)$. $(G)$ Structures of wild-type, Hsepi ${ }^{-1-}$, and Ndst-1 $1^{-/-}$HS with schematic indication of NS domains (black bars) and O-sulfation (circles). Notably, the Hsepi ${ }^{-1-} \mathrm{HS}$ is devoid of IdoA units and 2-O-sulfate groups, whereas the $N d s t-1^{-/-}$HS contains fewer $N$-sulfate groups and thus IdoA units and 2-O-sulfate groups. $(H)$ Illustration of a PDGF homodimer in interaction with an HS chain. A HS $\geq 12$-mer SAS domain joins the two PDGF monomers through interactions between its $N$-sulfated regions (black, separated by $N$-acetylated structure, gray) and the retention motifs (striped) on the protein. 


\section{Discussion}

The present study addresses the role of HS for the function of PDGF-BB in PC recruitment during vascular development. We show that both the recruitment of PCs along the growing blood vessels and the attachment of PCs to the ablumenal endothelial surface is defective in $N d s t-1^{-/-}$mice as a consequence of reduced HS $N$-sulfation in the developing vasculature. Detailed binding studies using size-defined oligosaccharide libraries, SAS fragments, and native HS isolated from mice deficient in Ndst-1 and Hsepi demonstrated that the overall degree of sulfation is a limiting factor for PDGF-BB retention by HS. Our HS-PDGF-BB binding studies further predicted that epimerization of GlcA to IdoA including subsequent 2-O-sulfation is unlikely to be essential for PDGF-BB retention in PC recruitment if compensated for by $N$ and 6-O-sulfate. Indeed, we find that PC recruitment is only marginally delayed and attachment of PC to the ablumenal endothelial surface is unaffected in $\mathrm{Hsepi}^{-/-}$ mice. Analysis of chemotaxis and signaling in $\mathrm{Ndst}_{-1}^{-1-}$ and $\mathrm{Hsepi}^{-/-}$MEF cells stimulated with PDGF-BB provided evidence for a particular involvement of $N$-sulfated HS in PDGFR $\beta$ signaling and directed cell migration. These data are the first to delineate the structure-function relationship of HS epitope modifications in PDGF$\mathrm{BB}$ retention and signaling during vascular development.

PDGF-BB is produced by the vascular endothelium and activates its cognate receptor tyrosine kinase, PDGFR $\beta$, on the PCs and vSMCs (for review, see Betsholtz 2004). Both Pdgf-b- and Pdgfrb-null mutants die at late gestation due to vascular defects associated with severe loss of PCs and vSMCs. Signaling through PDGFR $\beta$ stimulates cell migration, proliferation, and survival in cell culture. Elegant in vivo and biochemical data suggest that the level of PDGFR $\beta$ expression and the sum of pathways triggered by tyrosine phosphorylation of receptor upon activation determine the extent of expansion of the PC and vSMC population during mouse embryogenesis (Tallquist et al. 2003). Similarly, the levels of the ligand PDGF-BB regulate the expansion of the PC population (Hellström et al. 1999; Enge et al. 2002; Hammes et al. 2002), together indicating that PDGF-BB signaling through PDGFR $\beta$ gauges the expansion of the PC population. How PC migration and proliferation are coordinated to ensure effective PC recruitment in vascular development remains unclear.

First, insight recently arose from the phenotype of mice lacking the retention motif of PDGF-BB (Lindblom et al. 2003). Here, the incorporation of PCs into the vessel wall is severely defective, and the longitudinal recruitment of PCs along retinal vascular sprouts is delayed. In a model of tumor transplantation to $P d g f-b^{\text {ret/ret }}$ mice, ectopic tumor cell expression of PDGF-BB rescues the numbers of PCs; however, their attachment to the endothelium remains impaired (Abramsson et al. 2003). These data would agree with a mechanistic model in which directed migration and proper attachment of PCs is regulated by local PDGF-BB retention, whereas proliferation is retention-independent. Our present study on
Ndst-1 $1^{-/-}$mice shows that PDGF-BB retention, PC attachment, and longitudinal PC recruitment depend on $N$-sulfated HS, whereas PC proliferation does not. We suggest that vascular $N$-sulfated HS (Fig. 4) may act in conjunction with localized PDGF-BB production from the leading endothelial tip cell (Gerhardt et al. 2003) to generate localized short-range gradients through PDGF$\mathrm{BB}$ retention on the endothelial surface or perivascular ECM to direct PC migration and attachment. We provide two pieces of direct evidence for quantitative loss of PDGF-BB retention on Ndst-1-deficient tissue: First, isolated HS from $N d s t-1^{-/-}$embryos was poorly retained in physiological ionic conditions on a PDGF-BB affinity chromatography column (Fig. 7A-C), and secondly, cells isolated from $\mathrm{Ndst}_{-1} \mathrm{1}^{-/}$embryos and transfected with a PDGF-BB expression vector accumulated PDGF-BB in the medium in contrast to similarly transfected Ndst$1^{+/+}$cells (Fig. 7D).

Genetic studies indicate that NDST-1 is the major Nsulfating enzyme in HS biosynthesis (Grobe et al. 2002). NDST-2 is also ubiquitously expressed during development, yet mice lacking NDST-2 produce normal HS and have no vascular defects (Forsberg et al. 1999). However, HS in Ndst-1 mutants contains residual $N$-sulfates (as well as associated IdoA and $O$-sulfate groups) that may be ascribed to redundant effects of NDST-2. These remaining modifications explain the minor residual PDGFBB affinity of $N d s t-1^{-/-}$HS (Fig. 7C), and the attenuated $N d s t-1^{-1-}$ as compared with the $P d g f-b^{\text {ret/ret }}$ vascular phenotype (Fig. 1). The severely compromised PDGF-BB binding of $\mathrm{Ndst-1^{-/ }} \mathrm{HS}$ is explained by the structural requirements for such binding, elucidated in the present study. Adequate binding of PDGF-BB requires $\geq 12$-mer SAS domains with appropriately spaced $N$-sulfated subdomains (Fig. 9H); i.e., structures that are common in wild-type HS but rare in Ndst-1-/- HS (Fig. 9G).

Our biochemical data indicate that in addition to $N$ sulfation, O-sulfate groups are needed to promote HSPDGF-BB interaction. However, no preference for any particular sequence within the $N$-sulfated domains was detected, using variously $O$-sulfated oligosaccharide libraries as affinity probes (Fig. 6). We conclude that adequate PDGF-BB binding depends on long, although rare, NS domains or appropriately spaced and O-sulfated NS domains (SAS domains), without any specific sequence requirement. This proposal is supported by the PDGFBB-binding properties of HS isolated from $\mathrm{Hsepi}^{-/-}$mice (Fig. 7B), and by the associated vascular phenotype (Fig. 8). The binding properties, approaching those of wildtype HS, as well as the comparatively mild vascular phenotype indicate that the HS produced in $\mathrm{Hsepi}^{-/-}$mice, in spite of its lack of IdoA and severely perturbed $O$ sulfation pattern, is capable of functional interaction with the growth factor. The $\mathrm{Hsepi}^{-/-} \mathrm{HS}$ is extensively

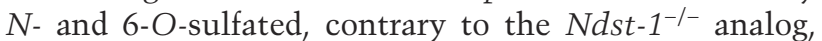
and thus apparently may interact with PDGF-BB either through contiguous $N$-sulfated regions or SAS domains (Fig. 9G,H). The lack of conformationally flexible IdoA units in $\mathrm{Hsepi}^{-/-} \mathrm{HS}$, which are generally believed to promote protein apposition, and the absence of clustered 
2-O- and 6-O-sulfate groups only marginally affect PDGF-BB binding.

Our present data identify local retention of PDGF-BB as a critical element in PC recruitment and indicate that this retention is required for directed migration and attachment of PCs, with little importance for PC proliferation. This differential requirement of HS for PC migration and proliferation could reflect alterations of downstream signaling. Previous work has provided little evidence for modification of PDGF-BB signaling through HS. Exogenously added heparin did not appear to alter the affinity of PDGFR $\beta$-PDGF-BB binding or signaling through PDGFR $\beta$ in HS-deficient CHO cells (Rolny et al. 2002). We studied PDGFR $\beta$ phosphorylation using an antibody that recognizes one of two tyrosine residues important for PI3K binding (Y750 in mouse). Although we can confirm that PDGF-BB is capable of inducing receptor phosphorylation in $N d s t-1^{-/-}$cells, we find a significant reduction, suggesting that $N$-sulfated HS produced by the responding cells modifies PDGFR $\beta$ signaling. Importantly, Hsepi-/- cells showed no difference in PDGFR $\beta$ signaling compared with wild-type cells. The PI3K-AKT pathway has previously been suggested to be most important for PC recruitment and is a major pathway in cell migration (Tallquist et al. 2003). Accordingly, cells carrying PDGFR $\beta$ with phenylalanine substitutions of the tyrosine residues (Y-F mutations) at positions 739 and 750 required for PI3K binding are compromised in downstream PDGF-BB signaling, showing reduced AKT and Erk MAPK phosphorylation (Tallquist et al. 2003). Additional Y-F mutations important for SHP2 and RASGap binding lead to additional signaling defects and a further reduction in PC recruitment in vivo. We find a very similar pattern of signaling defects in $\mathrm{Ndst}-1^{-/-}$ cells-e.g., reduced phosphorylation of Erk1, Erk2, and SHP2 (Fig. 9F)-providing the first evidence for HS modifications affecting PDGF-BB signaling. We further find reduced chemotaxis toward PDGF-BB in Ndst-1-1- cells, together suggesting that the defective longitudinal recruitment of PCs in vivo may indeed be caused by deficient PDGF-BB signaling pathways involved in cell migration. Interestingly, phosphorylation of PDGFR $\beta$ and AKT as well as cell motility were increased in unstimulated $N d s t-1^{-/-}$cells (Fig. 9E,F), indicating that reduced $N$-sulfation of HS could affect PDGFR $\beta$ activity and cell motility independent of ligand binding. The reason for this effect is unclear and warrants further investigation. Increased motility may by itself lead to reduced cell attachment and could partially explain the observed PC detachment in Ndst-1-1- embryos. Integrin receptors involved in cell attachment have been shown to directly activate PDGFR $\beta$ independent of ligand binding (Yamada and Even-Ram 2002). Integrins have also been suggested to interact with HS in focal adhesion assembly (for review, see Couchman and Woods 1999), and cell adhesion of vSMC and tumor cells (Beauvais and Rapraeger 2004), lending support to the idea that HS can function to enhance attachment while reducing migration of vSMC (Koyama et al. 1998). Thus, it is possible that the PC deficiencies in Ndst-1-1- embryos reflect a combina- tion of defects involving PDGF-BB retention and PDGFR $\beta$ signaling as well as integrin-mediated cell attachment and migration control. It is unclear, however, whether the increased cell motility and basal receptor activation in the absence of ligand would necessarily aggravate the PDGF-BB-dependent defects or rather partially ameliorate these, correlating with the somewhat milder PC phenotype in $N d s t-1^{-/-}$compared with Pdgf$b^{\text {ret/ret }}$ embryos. However, the observed detachment of PCs in Pdgf- $b^{\text {ret/ret }}$ mice demonstrates that the loss of PDGF-BB retention in itself is sufficient to cause the PC phenotype observed in $N d s t-1^{-/-}$embryos, arguing that potential PDGF-BB-independent effects of HS alterations in vitro are unlikely to play a major role in PC recruitment defects in vivo.

An alternative mechanistic model could involve establishment of a ternary complex in which, similar to FGFR signaling, both the receptor and the ligand directly interact with HS (Powell et al. 2002). Such an interaction could function to enhance receptor signaling in the presence of ligand, but also help keep the receptor silent when ligand is not bound. However, to our knowledge evidence for direct interaction of HS with PDGFR is not available, and the precise structure and stoichiometry of the PDGF-BB-PDGFR $\beta$ complex in the presence or absence of adequately $N$-sulfated HS chains has not been solved. Staining for $N$-sulfated domains in HS in vivo using the HepSS-1 antibody showed that these epitopes are tightly associated with the endothelial surface (Fig. 4), providing an ideal interface for the formation of potential ternary complexes only when PCs are tightly associated with the endothelial cells. Whether the relevant HS is produced by the endothelium or the PCs remains to be shown. For the related growth factor VEGF-A, a recent study demonstrated that HS can function in trans to potentiate VEGF receptor-mediated angiogenesis in chimeric embroid bodies (Jakobsson et al. 2006). In analogy, it is tempting to speculate that PDGF-BB and $N$ sulfated HS are produced by the same cell (the endothelium) so that maximal activation of PDGFR $\beta$ on PCs (in trans) occurs only when PCs are intimately associated with the endothelial surface.

\section{Materials and methods}

\section{Animals}

Animals were housed in individually ventilated cages under barrier conditions in the transgenic core facility of the Karolinska Institute, Stockholm; the Biomedical Center, Uppsala University; and at the Royal Veterinary College, London. Pdgf-bret mutants, Ndst-1 mutants, and Hsepi mutant mice were on a C57Bl/6J background (backcrossed for at least 10 generations) and were genotyped by PCR as previously described (Abramsson et al. 2003; Li et al. 2003; Holmborn et al. 2004).

\section{Immunohistochemistry}

Embryos were isolated at E10.25-E12.5 and fixed in 4\% paraformaldehyde, phosphate-buffered saline at $4^{\circ} \mathrm{C}$ for $4-16 \mathrm{~h}$. 
Hindbrains were dissected clean from other tissues and wholemount-stained as previously described (Ruhrberg et al. 2002; Gerhardt et al. 2003). Blood vessels were detected using biotinylated Griffonia simplicifolia isolectin-B4 (20 $\mu \mathrm{g} / \mathrm{mL}$; Sigma), and PCs were labeled using rabbit anti-NG2 antibody (1:200; Chemicon). HS was detected using HepSS-1 antibody (1:200; Seikagaku) (Kure and Yoshie 1986; van den Born et al. 2005). Secondary antibodies conjugated with the appropriate fluorochrome-Alexa Fluor 488, 568, or 633 (Molecular Probes; Invitrogen)-were used. Hindbrains were mounted on glass slides with Mowiol supplemented with anti-bleaching agent (1,4-diazabicyclo-2.2.2-octane; Sigma). Mounted hindbrains and sections were analyzed by conventional light and fluorescence microscopy using a Nikon E800 microscope and Zeiss Axiovert 200 equipped with digital cameras (Nikon and Zeiss) and by confocal laser scanning microscopy using a Zeiss LSM Meta 510 (Swegene Gothenburg, Sweden; CMB Karolinska Institute; and London Research Institute-Cancer Research UK). Digital images were processed using Volocity (Improvision) and Adobe Photoshop 7.0.

Measurements of PC coverage and detachment were made as described previously (Abramsson et al. 2003) using Volocity (Improvision) (at least six microscopic fields were counted for each hindbrain sample). All results are expressed as mean \pm SD. Differences between experimental groups were analyzed by Student's $t$-test using two-tailed distribution and the two-sample unequal variance. $P<0.05$ was considered statistically significant. Assessment of PC recruitment was performed by measuring the distance from the tips of vascular sprouts that extend toward the avascular periphery to the leading edge of the first PC process (at least 15 sprouts were measured for each hindbrain).

\section{PC proliferation in vivo}

BrdU (5-bromo 2'-deoxyuridine; Invitrogen) was injected at 50 $\mathrm{mg} / \mathrm{kg}$ body weight intraperitoneally into pregnant females $2 \mathrm{~h}$ before collecting embryos. Embryos (E11.5) were fixed and hindbrains were dissected as detailed above. Samples were passed through a methanol/PBT (PBS, $0.1 \%$ Tween 20 ) series before 30 min of proteinase K treatment $(10 \mu \mathrm{g} / \mathrm{mL}$ in PBT $)$ followed by 10 min in glycine $(2 \mathrm{mg} / \mathrm{mL}$ in PBT), two washes in PBT, and post-fixation for $20 \mathrm{~min}$ in $4 \% \mathrm{PFA} / 0.1 \%$ glutaraldehyde in PBT. After washing in PBT, samples were equilibrated in DNase I buffer ( $50 \mathrm{mM}$ Tris- $\mathrm{HCl}, 10 \mathrm{mM} \mathrm{MgCl}_{2}$ at $\mathrm{pH} 7.5$ ) and incubated for $2 \mathrm{~h}$ in DNase I $(0.1 \mathrm{U} / \mu \mathrm{L})$ at $37^{\circ} \mathrm{C}$. DNase was heatinactivated for $10 \mathrm{~min}$ at $70^{\circ} \mathrm{C}$ in $50 \mathrm{mM}$ Tris- $\mathrm{HCl}(\mathrm{pH} 7.5)$, followed by washes in ice-cold Tris-HCl. After two washes in PBT, unspecific binding of antibodies was blocked by $1 \%$ BSA/ $0.5 \%$ Tween 20 in PBS for 30 min. Samples were labeled using Isolectin-B4 as described (Gerhardt et al. 2003). PCs were labeled using rat anti-mouse PDGFR $\beta$ (1:200 in 0.5\% BSA/0.25\% Tween 20/PBS; clone APB5, eBioscience). Biotin-Isolectin-B4 and PDGFR $\beta$ antibody were detected with streptavidin Alexa Fluor 633 (1:200; Molecular Probes; Invitrogen) and donkey anti-rat rhodamine (TRITC) conjugate (1:100; Jackson Immunoresearch Laboratories), respectively. BrdU was detected with mouse anti-BrdU Alexa Fluor 488 (1:50; Molecular Probes; Invitrogen). Nuclear counterlabeling was performed using Hoechst 33258 (Sigma-Aldrich). Samples were flat-mounted and cover-slipped using Moviol.

Proliferating PCs were assessed by nuclear BrdU staining on four-channel confocal image stacks at 1 - $\mu \mathrm{m} z$-intervals acquired using a $63 \times$ lens. Twenty image stacks of 10 - to 15 - $\mu \mathrm{m}$ total $\mathrm{z}$-dimension were analyzed for each genotype $\left(\mathrm{Ndst-1^{-1- }}\right.$ and Ndst $-1^{+/+}$; five image stacks/hindbrain, four hindbrains E11.5 pergenotype). Examples of image stacks are shown in Supplementary Figure 1.

\section{PDGF-BB signaling assay}

Ndst-1-/-, $\mathrm{Hsepi}^{-/-}$, or wild-type MEFs were seeded in 12-well culture plates. At $100 \%$ confluency, they were washed three times in serum-free medium and starved for $2 \mathrm{~h}$ in serum-free medium. PDGF-BB (P4056; Sigma) was added at a $100 \mathrm{ng} / \mathrm{mL}$ concentration. After $10 \mathrm{~min}$ of incubation at $37^{\circ} \mathrm{C}$, the cells were lysed in $180 \mu \mathrm{L}$ of boiling nonreducing SDS-sample buffer and sonicated. Cell extracts were separated on NuPAGE 4\%$12 \%$ Bis-Tris gel (Invitrogen) and transferred to a Hybond-P PVDF membrane (GE Healthcare Biosciences). The membrane was incubated with the antibodies provided in the PathScan PDGFR Tyrosine Kinase Activity Assay Kit (7180; Cell Signaling Technology). The membranes were developed using LumiGLO provided with the kit. The assay was performed in triplicate.

\section{PDGF-BB chemotaxis assay}

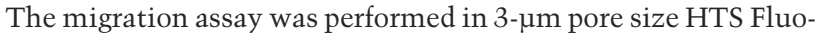
roblok chamber inserts (BD Falcon, product number 351151). Ndst-1 ${ }^{-1-}, \mathrm{Hsepi}^{-1-}$, or wild-type MEFs were washed three times with serum-free medium and then preincubated with $5 \mu \mathrm{M}$ calcein (C3100MP; Invitrogen). Subsequently, 40,000 cells were plated into the chamber. These were transferred into 24-well plates containing serum-free medium with or without $20 \mathrm{ng} / \mathrm{mL}$ PDGF-BB. After overnight incubation, the cells in the bottom part of the chamber were counted on an Axiovert 200M fluorescence microscope (Zeiss). At least five microscopic fields $\left(0.564 \mathrm{~mm}^{2}\right)$ per chamber were analyzed. Data are represented as average cell number/field \pm standard deviation. The assay was performed in triplicate (independent assays, cell batch).

\section{PDGF-BB proximity ligation assay}

Ndst-1-1-, Hsepi-/-, or wild-type MEFs were grown on T-75 plates and transfected with full-length human $P d g f-b$ cDNA (OriGene, product number TC111665) using Lipofectamine 2000 (Invitrogen). The next day, media were exchanged and, after $48 \mathrm{~h}$ of incubation, collected and frozen. Cells were washed three times with PBS and lysed in $10 \mathrm{mM}$ Tris (pH 7.4), $150 \mathrm{mM}$ $\mathrm{NaCl}, 0.5 \%$ NP-40, 1 mM EDTA, and 1 mM EGTA buffer with total protease inhibitor cocktail (Roche) for $30 \mathrm{~min}$ at $4^{\circ} \mathrm{C}$. The extract was centrifuged for $30 \mathrm{~min}$ at $13,000 \mathrm{rpm}$, at $4^{\circ} \mathrm{C}$, and the supernatants were frozen. The total protein concentration was determined using the BCA Protein Assay Kit (Pierce). PDGF-BB was measured in lysates and medium from four plates for each genotype. Measurements were done in triplicate using triple proximity ligation assay as described (Schallmeiner et al. 2007).

\section{PDGF-affinity matrix}

PDGF-BB was produced in an Escherichia coli expression system as described (Lustig et al. 1996). PDGF-BB (250 $\mu \mathrm{g})$ was coupled to activated $\mathrm{CH}$-Sepharose CL4B gel matrix (0.5 g dry weight) in a total volume of $2 \mathrm{~mL}$ according to the manufacturer's instructions (GE Healthcare Biosciences). To protect the ligand-binding site on the protein from coupling to the beads, 
heparin $(2 \mathrm{mg})$, pretreated with $\mathrm{HNO}_{2}$ at $\mathrm{pH} 3.9$ to eliminate all $\mathrm{N}$-unsubstituted glucosamine residues, was added.

\section{Saccharide reagents}

HS chains were isolated from mouse embryos as described (Ledin et al. 2004), and were $N-\left[{ }^{3} \mathrm{H}\right]$ acetylated after $N$-deacetylation by hydrazinolysis for $2 \mathrm{~h}$ as described (Hook et al. 1982). The products had specific activities of $5 \times 10^{4}, 4.8 \times 10^{4}$, and $3.3 \times 10^{4}$ counts per minute $(\mathrm{cpm}){ }^{3} \mathrm{H}$ per microgram for wild-

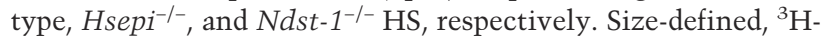
end-labeled oligosaccharides from native bovine lung heparin were created by partial deamination at $\mathrm{pH} 1.5$ and reduction with $\mathrm{NaB}^{3} \mathrm{H}_{4}$, as described earlier (Spillmann et al. 1998). Similarly, pig intestine HS was cleaved by partial deamination at $\mathrm{pH}$ 1.5 to yield fragments containing mixed acetyl and sulfate $N$ substituents (SAS fragments) as described (Kreuger et al. 2002). The size of the SAS fragments was determined on a Superdex 30 column (GE Healthcare Biosciences) in $0.5 \mathrm{M} \mathrm{NH}_{4} \mathrm{HCO}_{3}$, using a flow rate of $0.5 \mathrm{~mL} / \mathrm{min}$. The presence of GlcNAc residues in SAS oligosaccharides was ascertained by $N$-deacetylation (hydrazinolysis for $5 \mathrm{~h}$ ) followed by selective deaminative cleavage (pH 3.9) at generated $N$-unsubstituted glucosamine units (Shively and Conrad 1976). The resultant reduction in size of the labeled oligomer was demonstrated by gel chromatography as described above.

Radiolabeled oligosaccharide libraries were generated by chemoenzymatic modification of heparin, essentially as described (Jemth et al. 2002). Bovine lung heparin was 6-O-desulfated and partially 2-O-desulfated by treatment with dimethyl sulfoxide/ methanol $[9: 1(\mathrm{v} / \mathrm{v})]$, and was then re- $N$-sulfated as described earlier (Feyzi et al. 1997b). Oligosaccharides generated from 2.5 $\mathrm{mg}$ of the product by partial cleavage with $\mathrm{HNO}_{2}(\mathrm{pH} 1.5)$ were reduced with $5 \mathrm{mCi}$ of $\mathrm{NaB}^{3} \mathrm{H}_{4}$, yielding a mixture of evennumbered oligomers with reducing-terminal ${ }^{3} \mathrm{H}$-labeled 2,5-anhydromannitol (aManR) residues. Size-defined oligosaccharides were recovered by gel chromatography of the mixture and further separated with regard to charge by anion-exchange HPLC as described (Ten Dam et al. 2006). Oligosaccharides containing from one to five 2-O-sulfate groups were pooled, desalted, and separately subjected to enzymatic $O$-sulfation (primarily 6-Osulfation) in reaction mixtures (final volume, $100 \mu \mathrm{L}$ ) containing $25 \%(\mathrm{v} / \mathrm{v})$ of mouse mastocytoma microsomal protein $(20$ $\mathrm{mg} / \mathrm{mL}$ ), $1 \mathrm{mM} \mathrm{3'}$-phosphoadenosine-5-phosphosulfate (PAPS), $10 \mathrm{mM} \mathrm{MnCl}_{2}, 3.5 \mu \mathrm{M} \mathrm{NaF}, 0.3 \%$ (v/v) Triton X-100, and 50 $\mathrm{mM}$ HEPES (pH 7.4). Incubations were performed for $30 \mathrm{~min}$ at $37^{\circ} \mathrm{C}$. Reaction products were desalted, reanalyzed by anionexchange HPLC as before, and used in PDGF-BB-binding assays.

\section{PDGF-affinity chromatography}

PDGF-substituted beads $(0.8 \mathrm{~mL})$ were washed with $5 \mathrm{~mL}$ of $2 \mathrm{M}$ $\mathrm{NaCl}$ in $50 \mathrm{mM}$ Tris/ $\mathrm{HCl}(\mathrm{pH} 7.4)$ to remove protecting heparin, and were then transferred into a $10-\mathrm{mL}$ column (Bio-Rad) and equilibrated with $50 \mathrm{mM}$ Tris- $\mathrm{HCl}(\mathrm{pH}$ 7.4). Sample oligo- and polysaccharides $\left({ }^{3} \mathrm{H}\right.$-end-labeled HS and heparin oligosaccharides or $N-\left[{ }^{3} \mathrm{H}\right]$ acetyl-labeled HS chains) were applied on the column in $0.5 \mathrm{~mL}$ of $50 \mathrm{mM}$ Tris- $\mathrm{HCl}(\mathrm{pH} 7.4)$ and allowed to incubate for $30 \mathrm{~min}$ at $4^{\circ} \mathrm{C}$. The column was then eluted using a stepwise $\mathrm{NaCl}$ gradient in $50 \mathrm{mM}$ Tris- $\mathrm{HCl}(\mathrm{pH} 7.4)$, as indicated in the figure legends, and effluent fractions were analyzed by scintillation counting. Preparative affinity chromatography was performed in a similar fashion. Eluates were pooled as indicated into unbound (eluted at $0.2 \mathrm{M} \mathrm{NaCl}$ ) and bound $(\geq 0.25$ $\mathrm{M} \mathrm{NaCl}$ ) fractions, and desalted on PD-10 columns for further characterization.

\section{Acknowledgments}

We acknowledge the Swegene Centre for Cellular Imaging at Gothenburg University for the use of imaging equipment. We thank Daniel Zicha (Light Microscopy, Cancer Research UK) for excellent help with imaging technique. We thank Gunilla Pettersson and Eva Gottfridsson for valuable help with the preparation of HS samples. This work was supported by Cancer Research UK, the Swedish Cancer Society, the Swedish Research Council, the Foundation for Strategic Research (A303:156e), Polysackaridforskning $\mathrm{AB}$ and Gustaf V:s 80-årsfond, the Association of International Cancer Research (AICR), the Swedish Cancer Foundation, and the Inga-Britt and Arne Lundberg Foundation.

\section{References}

Abramsson, A., Lindblom, P., and Betsholtz, C. 2003. Endothelial and nonendothelial sources of PDGF-B regulate pericyte recruitment and influence vascular pattern formation in tumors. J. Clin. Invest. 112: 1142-1151.

Beauvais, D.M. and Rapraeger, A.C. 2004. Syndecans in tumor cell adhesion and signaling. Reprod. Biol. Endocrinol. 2: 3.

Betsholtz, C. 2004. Insight into the physiological functions of PDGF through genetic studies in mice. Cytokine Growth Factor Rev. 15: 215-228.

Bjarnegard, M., Enge, M., Norlin, J., Gustafsdottir, S., Fredriksson, S., Abramsson, A., Takemoto, M., Gustafsson, E., Fassler, R., and Betsholtz, C. 2004. Endothelium-specific ablation of PDGFB leads to pericyte loss and glomerular, cardiac and placental abnormalities. Development 131: 18471857.

Couchman, J.R. and Woods, A. 1999. Syndecan-4 and integrins: Combinatorial signaling in cell adhesion. J. Cell Sci. 112: 3415-3420.

Enge, M., Bjarnegard, M., Gerhardt, H., Gustafsson, E., Kalen, M., Asker, N., Hammes, H.P., Shani, M., Fassler, R., and Betsholtz, C. 2002. Endothelium-specific platelet-derived growth factor-B ablation mimics diabetic retinopathy. EMBO J. 21: 4307-4316.

Esko, J.D. and Lindahl, U. 2001. Molecular diversity of heparan sulfate. J. Clin. Invest. 108: 169-173.

Esko, J.D. and Selleck, S.B. 2002. Order out of chaos: Assembly of ligand binding sites in heparan sulfate. Annu. Rev. Biochem. 71: 435-471.

Feyzi, E., Lustig, F., Fager, G., Spillmann, D., Lindahl, U., and Salmivirta, M. 1997a. Characterization of heparin and heparan sulfate domains binding to the long splice variant of platelet-derived growth factor A chain. J. Biol. Chem. 272: 5518-5524.

Feyzi, E., Trybala, E., Bergstrom, T., Lindahl, U., and Spillmann, D. $1997 b$. Structural requirement of heparan sulfate for interaction with herpes simplex virus type 1 virions and isolated glycoprotein C. J. Biol. Chem. 272: 24850-24857.

Ford-Perriss, M., Guimond, S.E., Greferath, U., Kita, M., Grobe, K., Habuchi, H., Kimata, K., Esko, J.D., Murphy, M., and Turnbull, J.E. 2002. Variant heparan sulfates synthesized in developing mouse brain differentially regulate FGF signaling. Glycobiology 12: 721-727.

Forsberg, E., Pejler, G., Ringvall, M., Lunderius, C., TomasiniJohansson, B., Kusche-Gullberg, M., Eriksson, I., Ledin, J., Hellman, L., and Kjellen, L. 1999. Abnormal mast cells in mice deficient in a heparin-synthesizing enzyme. Nature 400: $773-776$.

Gallagher, J.T. 2001. Heparan sulfate: Growth control with a restricted menu. J. Clin. Invest. 108: 357-361. 
Gerhardt, H. and Betsholtz, C. 2003. Endothelial-pericyte interactions in angiogenesis. Cell Tissue Res. 314: 15-23.

Gerhardt, H., Golding, M., Fruttiger, M., Ruhrberg, C., Lundkvist, A., Abramsson, A., Jeltsch, M., Mitchell, C., Alitalo, K., Shima, D., et al. 2003. VEGF guides angiogenic sprouting utilizing endothelial tip cell filopodia. J. Cell Biol. 161: 1163-1177.

Grobe, K., Ledin, J., Ringvall, M., Holmborn, K., Forsberg, E., Esko, J.D., and Kjellen, L. 2002. Heparan sulfate and development: Differential roles of the $\mathrm{N}$-acetylglucosamine $\mathrm{N}$ deacetylase $/ N$-sulfotransferase isozymes. Biochim. Biophys. Acta 1573: 209-215.

Grobe, K., Inatani, M., Pallerla, S.R., Castagnola, J., Yamaguchi, Y., and Esko, J.D. 2005. Cerebral hypoplasia and craniofacial defects in mice lacking heparan sulfate $\mathrm{Ndst} 1$ gene function. Development 132: 3777-3786.

Hacker, U., Nybakken, K., and Perrimon, N. 2005. Heparan sulphate proteoglycans: The sweet side of development. Nat. Rev. Mol. Cell Biol. 6: 530-541.

Hammes, H.P., Lin, J., Renner, O., Shani, M., Lundqvist, A., Betsholtz, C., Brownlee, M., and Deutsch, U. 2002. Pericytes and the pathogenesis of diabetic retinopathy. Diabetes 51: 3107-3112.

Hellström, M., Kalén, M., Lindahl, P., Abramsson, A., and Betsholtz, C. 1999. Role of PDGF-B and PDGFR- $\beta$ in recruitment of vascular smooth muscle cells and pericytes during embryonic blood vessel formation in the mouse. Development 126: 3047-3055.

Holmborn, K., Ledin, J., Smeds, E., Eriksson, I., Kusche-Gullberg, M., and Kjellen, L. 2004. Heparan sulfate synthesized by mouse embryonic stem cells deficient in NDST1 and NDST2 is 6-O-sulfated but contains no $\mathrm{N}$-sulfate groups. $J$. Biol. Chem. 279: 42355-42358.

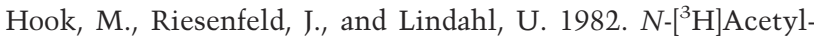
labeling, a convenient method for radiolabeling of glycosaminoglycans. Anal. Biochem. 119: 236-245.

Jakobsson, L., Kreuger, J., Holmborn, K., Lundin, L., Eriksson, I., Kjellen, L., and Claesson-Welsh, L. 2006. Heparan sulfate in trans potentiates VEGFR-mediated angiogenesis. Dev. Cell 10: 625-634.

Jemth, P., Kreuger, J., Kusche-Gullberg, M., Sturiale, L., Gimenez-Gallego, G., and Lindahl, U. 2002. Biosynthetic oligosaccharide libraries for identification of protein-binding heparan sulfate motifs. Exploring the structural diversity by screening for fibroblast growth factor (FGF)1 and FGF2 binding. J. Biol. Chem. 277: 30567-30573.

Koyama, N., Kinsella, M.G., Wight, T.N., Hedin, U., and Clowes, A.W. 1998. Heparan sulfate proteoglycans mediate a potent inhibitory signal for migration of vascular smooth muscle cells. Circ. Res. 83: 305-313.

Kreuger, J., Matsumoto, T., Vanwildemeersch, M., Sasaki, T., Timpl, R., Claesson-Welsh, L., Spillmann, D., and Lindahl, U. 2002. Role of heparan sulfate domain organization in endostatin inhibition of endothelial cell function. EMBO J. 21: 6303-6311.

Kreuger, J., Spillmann, D., Li, J.P., and Lindahl, U. 2006. Interactions between heparan sulfate and proteins: The concept of specificity. J. Cell Biol. 174: 323-327.

Kure, S. and Yoshie, O. 1986. A syngeneic monoclonal antibody to murine Meth-A sarcoma (HepSS-1) recognizes heparan sulfate glycosaminoglycan (HS-GAG): Cell density and transformation dependent alteration in cell surface HS-GAG defined by HepSS-1. J. Immunol. 137: 3900-3908.

LaRochelle, W.J., May-Siroff, M., Robbins, K.C., and Aaronson, S.A. 1991. A novel mechanism regulating growth factor association with the cell surface: Identification of a PDGF re- tention domain. Genes \& Dev. 5: 1191-1199.

Ledin, J., Staatz, W., Li, J.P., Gotte, M., Selleck, S., Kjellen, L., and Spillmann, D. 2004. Heparan sulfate structure in mice with genetically modified heparan sulfate production. J. Biol. Chem. 279: 42732-42741.

Li, J.P., Gong, F., Hagner-McWhirter, A., Forsberg, E., Abrink, M., Kisilevsky, R., Zhang, X., and Lindahl, U. 2003. Targeted disruption of a murine glucuronyl C5-epimerase gene results in heparan sulfate lacking L-iduronic acid and in neonatal lethality. J. Biol. Chem. 278: 28363-28366.

Lin, X. 2004. Functions of heparan sulfate proteoglycans in cell signaling during development. Development 131: 60096021.

Lindahl, P., Johansson, B.R., Levéen, P., and Betsholtz, C. 1997. Pericyte loss and microaneurysm formation in PDGF-B-deficient mice. Science 277: 242-245.

Lindblom, P., Gerhardt, H., Liebner, S., Abramsson, A., Enge, M., Hellstrom, M., Backstrom, G., Fredriksson, S., Landegren, U., Nystrom, H.C., et al. 2003. Endothelial PDGF-B retention is required for proper investment of pericytes in the microvessel wall. Genes \& Dev. 17: 1835-1840.

Lortat-Jacob, H., Turnbull, J.E., and Grimaud, J.A. 1995. Molecular organization of the interferon $\gamma$-binding domain in heparan sulphate. Biochem. J. 310: 497-505.

Lustig, F., Hoebeke, J., Ostergren-Lunden, G., Velge-Roussel, F., Bondjers, G., Olsson, U., Ruetschi, U., and Fager, G. 1996 Alternative splicing determines the binding of platelet-derived growth factor (PDGF-AA) to glycosaminoglycans. Biochemistry 35: 12077-12085.

Östman, A., Andersson, M., Betsholtz, C., Westermark, B., and Heldin, C.-H. 1991. Identification of a cell retention signal in the B-chain of PDGF and in the long splice version of the A-chain. Cell Regul. 2: 503-512.

Powell, A.K., Fernig, D.G., and Turnbull, J.E. 2002. Fibroblast growth factor receptors 1 and 2 interact differently with heparin/heparan sulfate. Implications for dynamic assembly of a ternary signaling complex. J. Biol. Chem. 277: 2855428563.

Ringvall, M., Ledin, J., Holmborn, K., van Kuppevelt, T., Ellin, F., Eriksson, I., Olofsson, A.M., Kjellen, L., and Forsberg, E. 2000. Defective heparan sulfate biosynthesis and neonatal lethality in mice lacking $N$-deacetylase $/ N$-sulfotransferase1. J. Biol. Chem. 275: 25926-25930.

Robinson, C.J., Mulloy, B., Gallagher, J.T., and Stringer, S.E. 2006. VEGF165-binding sites within heparan sulfate encompass two highly sulfated domains and can be liberated by K5 lyase. J. Biol. Chem. 281: 1731-1740.

Rolny, C., Spillmann, D., Lindahl, U., and Claesson-Welsh, L. 2002. Heparin amplifies platelet-derived growth factor (PDGF)-BB-induced PDGF $\alpha$-receptor but not PDGF $\beta$-receptor tyrosine phosphorylation in heparan sulfate-deficient cells. Effects on signal transduction and biological responses. J. Biol. Chem. 277: 19315-19321.

Ruhrberg, C., Gerhardt, H., Golding, M., Watson, R., Ioannidou, S., Fujisawa, H., Betsholtz, C., and Shima, D.T. 2002. Spatially restricted patterning cues provided by heparin-binding VEGF-A control blood vessel branching morphogenesis. Genes \& Dev. 16: 2684-2698.

Schallmeiner, E., Oksanen, E., Ericsson, O., Spångberg, L., Eriksson, S., Stenman, U., Pettersson, K., and Landegren, U. 2007. Sensitive protein detection via triple-binder proximity ligation assays. Nat. Methods Epub December 17, 2006; doi: $10.1038 /$ nmeth974.

Shively, J.E. and Conrad, H.E. 1976. Nearest neighbor analysis of heparin: Identification and quantitation of the products formed by selective depolymerization procedures. Biochem- 
istry 15: 3943-3950.

Spillmann, D., Witt, D., and Lindahl, U. 1998. Defining the interleukin-8-binding domain of heparan sulfate. J. Biol. Chem. 273: 15487-15493.

Stringer, S.E. and Gallagher, J.T. 1997. Specific binding of the chemokine platelet factor 4 to heparan sulfate. J. Biol. Chem. 272: 20508-20514.

Tallquist, M.D., French, W.J., and Soriano, P. 2003. Additive effects of PDGF receptor $\beta$ signaling pathways in vascular smooth muscle cell development. PLoS Biol. 1: E52.

Ten Dam, G.B., Kurup, S., van de Westerlo, E.M., Versteeg, E.M., Lindahl, U., Spillmann, D., and van Kuppevelt, T.H. 2006. 3-O-sulfated oligosaccharide structures are recognized by anti-heparan sulfate antibody HS4C3. J. Biol. Chem. 281: 4654-4662.

van den Born, J., Salmivirta, K., Henttinen, T., Ostman, N., Ishimaru, T., Miyaura, S., Yoshida, K., and Salmivirta, M. 2005. Novel heparan sulfate structures revealed by monoclonal antibodies. J. Biol. Chem. 280: 20516-20523.

Yabe, T., Hata, T., He, J., and Maeda, N. 2005. Developmental and regional expression of heparan sulfate sulfotransferase genes in the mouse brain. Glycobiology 15: 982-993.

Yamada, K.M. and Even-Ram, S. 2002. Integrin regulation of growth factor receptors. Nat. Cell Biol. 4: E75-E76. 


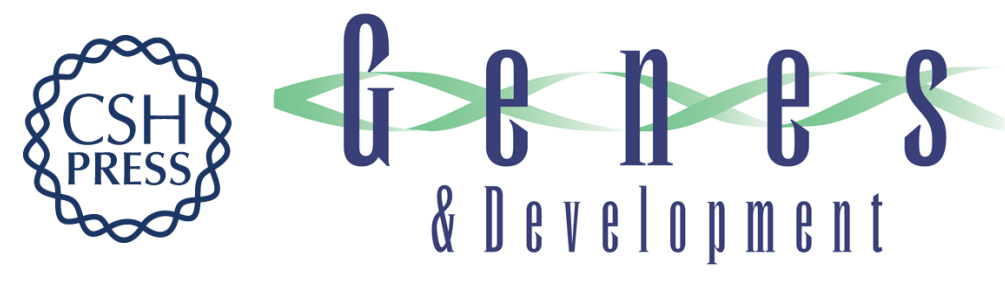

\section{Defective $\mathbf{N}$-sulfation of heparan sulfate proteoglycans limits PDGF-BB binding and pericyte recruitment in vascular development}

Alexandra Abramsson, Sindhulakshmi Kurup, Marta Busse, et al.

Genes Dev. 2007, 21:

Access the most recent version at doi:10.1101/gad.398207

Supplemental
Material http://genesdev.cshlp.org/content/suppl/2007/02/08/21.3.316.DC1

References This article cites 49 articles, 30 of which can be accessed free at:

http://genesdev.cshlp.org/content/21/3/316.full.html\#ref-list-1

License

Email Alerting Receive free email alerts when new articles cite this article - sign up in the box at the top

Service

right corner of the article or click here.

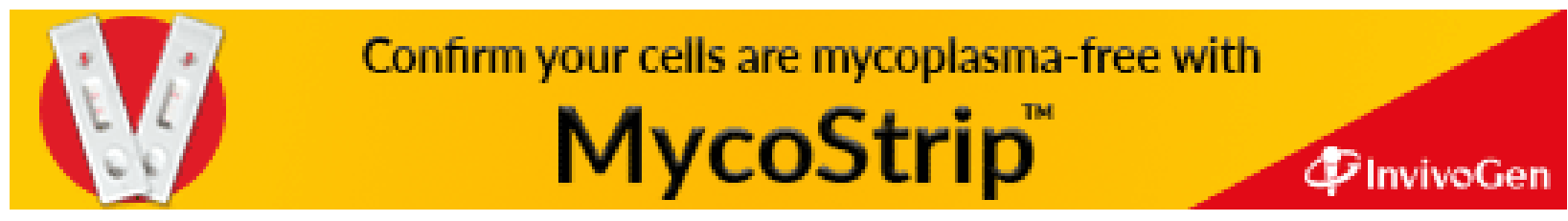

